\title{
The Austrian radiation monitoring network ARAD - best practice and added value
}

\author{
Marc Olefs ${ }^{1}$, Dietmar J. Baumgartner ${ }^{2}$, Friedrich Obleitner ${ }^{3}$, Christoph Bichler ${ }^{4,5}$, Ulrich Foelsche ${ }^{4,5}$, Helga Pietsch ${ }^{4}$, \\ Harald E. Rieder ${ }^{5,4,6}$, Philipp Weihs ${ }^{7}$, Florian Geyer ${ }^{1}$, Thomas Haiden ${ }^{8}$, and Wolfgang Schöner ${ }^{9,6}$ \\ ${ }^{1}$ ZAMG - Zentralanstalt für Meteorologie und Geodynamik, Vienna, Austria \\ ${ }^{2}$ Kanzelhöhe Observatory for Solar and Environmental Research, University of Graz, Graz, Austria \\ ${ }^{3}$ Institute of Atmospheric and Cryospheric Sciences, University of Innsbruck, Innsbruck, Austria \\ ${ }^{4}$ Institute for Geophysics, Astrophysics and Meteorology/Institute of Physics (IGAM/IP), University of Graz, Graz, Austria \\ ${ }^{5}$ Wegener Center for Climate and Global Change (WEGC), University of Graz, Graz, Austria \\ ${ }^{6}$ Austrian Polar Research Institute, Vienna, Austria \\ ${ }^{7}$ Institute for Meteorology, University of Natural Resources and Life Sciences Vienna, Vienna, Austria \\ ${ }^{8}$ European Centre for Medium-Range Weather Forecasts (ECMWF), Reading, UK \\ ${ }^{9}$ Institute for Geography and Regional Research University of Graz, Graz, Austria
}

Correspondence to: Marc Olefs (marc.olefs@zamg.ac.at)

Received: 26 August 2015 - Published in Atmos. Meas. Tech. Discuss.: 16 October 2015

Revised: 17 February 2016 - Accepted: 6 March 2016 - Published: 6 April 2016

\begin{abstract}
The Austrian RADiation monitoring network (ARAD) has been established to advance the national climate monitoring and to support satellite retrieval, atmospheric modeling and the development of solar energy techniques. Measurements cover the downward solar and thermal infrared radiation using instruments according to Baseline Surface Radiation Network (BSRN) standards. A unique feature of ARAD is its vertical dimension of five stations, covering an altitude range between about $200 \mathrm{~m}$ a.s.1 (Vienna) and $3100 \mathrm{~m}$ a.s.l. (BSRN site Sonnblick). The paper outlines the aims and scopes of ARAD, its measurement and calibration standards, methods, strategies and station locations. ARAD network operation uses innovative data processing for quality assurance and quality control, utilizing manual and automated control algorithms. A combined uncertainty estimate for the broadband shortwave radiation fluxes at all five ARAD stations, using the methodology specified by the Guide to the Expression of Uncertainty in Measurement indicates that relative accuracies range from 1.5 to $2.9 \%$ for large signals (global, direct: $1000 \mathrm{~W} \mathrm{~m}^{-2}$, diffuse: $500 \mathrm{~W} \mathrm{~m}^{-2}$ ) and from 1.7 to $23 \%$ (or 0.9 to $\left.11.5 \mathrm{~W} \mathrm{~m}^{-2}\right)$ for small signals $\left(50 \mathrm{~W} \mathrm{~m}^{-2}\right)$ (expanded uncertainties corresponding to the $95 \%$ confidence level). If the directional response error of the pyranometers and
\end{abstract}

the temperature response of the instruments and the data acquisition system (DAQ) are corrected, this expanded uncertainty reduces to 1.4 to $2.8 \%$ for large signals and to 1.7 to $5.2 \%$ (or $0.9-2.6 \mathrm{~W} \mathrm{~m}^{-2}$ ) for small signals. Thus, for large signals of global and diffuse radiation, BSRN target accuracies are met or nearly met (missed by less than 0.2 percentage points, pps) for $70 \%$ of the ARAD measurements after this correction. For small signals of direct radiation, BSRN targets are achieved at two sites and nearly met (also missed by less than $0.2 \mathrm{pps}$ ) at the other sites. For small signals of global and diffuse radiation, targets are achieved at all stations. Additional accuracy gains can be achieved in the future through additional measurements, corrections and a further upgrade of the DAQ. However, to improve the accuracy of measurements of direct solar radiation, improved instrument accuracy is needed. ARAD could serve as a useful example for establishing state-of-the-art radiation monitoring at the national level with a multiple-purpose approach. Instrumentation, guidelines and tools (such as the data quality control) developed within ARAD are intended to increase monitoring capabilities of global radiation and thus designed to allow straightforward adoption in other regions, without high development costs. 


\section{Introduction}

Radiative processes are key for both the natural and the anthropogenic dimension of the climate system as well as its changes. Firstly, the Earth's radiation budget plays an essential role in determining the thermal state of the land surface, the atmosphere and the oceans, thereby also strongly influencing the circulation of the latter two (Ohmura et al., 1998; Ramanathan, 1987). Secondly, the main anthropogenic influence on climate arises through modification of the Earth's radiation budget components (Intergovernmental Panel on Climate Change, 2014). Worldwide in situ ground-based and space-based measurements of radiative fluxes are thus performed to (a) improve the process understanding of the present climate system (e.g., Wild et al., 2015), (b) provide data for the validation and calibration of weather and climate models in order to understand processes in the past and future and/or to improve weather forecasts (Chevallier and Morcrette, 2000; Haiden and Trentmann, 2015; Wild et al., 2001) and (c) support solar energy applications (e.g., Gueymard, 2014).

Surface observations have the lowest degree of uncertainty and are therefore used to validate satellite measurements (Gupta et al., 2004). The most prominent, worldwide observational ground-based network for surface radiation fluxes is the Baseline Surface Radiation Network (BSRN), established in the early 1990s (Ohmura et al., 1998) by the World Climate Research Programme (WCRP). BSRN provides measurements with high accuracy and high temporal resolution, and comprises currently 54 sites in different climate regimes (König-Langlo et al., 2013). Another worldwide network providing surface radiative fluxes is the Global Energy Balance Archive (GEBA) (Gilgen and Ohmura, 1999).

Besides these global observational networks, several national surface radiation monitoring networks exist such as SURFRAD in the US (Augustine et al., 2000) or SACRaM in Switzerland (Wacker et al., 2011). These networks provide long-term observations for climate monitoring and aid process-level understanding on regional scales such as e.g., the European Alps.

The European Alpine region is known to react especially sensitively to both observed (Auer et al., 2007) and projected (Gobiet et al., 2014) global climate change. Therefore there is great need for long-term measurements of the radiative fluxes in Europe, particularly in the Alps, to better understand the drivers of observed and projected changes (e.g., Kotlarski et al., 2015; Marty et al., 2002; Philipona, 2013; Wild, 2009). Moreover, state-of-the-art regional climate models still show significant biases, considerably adding to the uncertainty of future climate change projections (e.g., Frei, 2003; Haslinger et al., 2013). To this aim, ultimately a dense network of highaccuracy surface observations of the radiative fluxes, especially in complex, densely populated alpine topography and adjacent lowlands, is needed where possible impacts of cli- mate change lead to great vulnerability and accurate estimates of the solar energy resources are needed due to the growing demand for renewable energies.

Large parts of the European Alps are within the national territory of Austria. The Austrian Alps are also part of the Greater Alpine Region (GAR) with a unique and outstanding long-term instrumental climatological data set (Auer et al., 2007). Significant Austrian contributions to the field of solar radiation and albedo measurements and respective developments of instrumentation date back to the 1950s and 1970s (e.g., Dirmhirn, 1951, 1957; Dirmhirn and Eaton, 1975; Dirmhirn and Trojer, 1955; Sauberer and Dirmhirn, 1952). In the meantime the standard meteorological station network of the Austrian Zentralanstalt für Meteorologie und Geodynamik (ZAMG), which includes the measurement of global horizontal irradiance using a Schenk star pyranometer, has evolved, from 20 stations in 1980 to 235 stations in 2015, the latter corresponding to a mean horizontal station distance of about $20 \mathrm{~km}$. In the 1970s and 1980s, surface radiation studies in Austria were focused on establishing radiation climatologies and increasing the process understanding based on the available station data (e.g., Neuwirth, 1980, 1983). From the mid-1990s until today, work related to ultraviolet (UV) radiation and health risks (e.g., Blumthaler et al., 1996; Rieder et al., 2010; Weihs et al., 2008, 2013), to the role of aerosols in alpine valleys (e.g., Blumthaler et al., 1997; Wuttke et al., 2012) and studies dealing with anthropogenic influences on radiative fluxes and solar energy (e.g., Weihs et al., 2015) predominated in Austria.

With this background the Austrian RADiation monitoring network (ARAD) was founded in the year 2010, following an initiative of ZAMG in cooperation with the universities of Graz and Innsbruck, and the University of Natural Resources and Life Sciences (BOKU) in Vienna. In its original concept, ARAD has to fulfill three major requirements: (i) to provide a state-of-the-art national radiation monitoring network; (ii) to provide data for atmospheric model/satellite data calibration and validation and (iii) to provide high-accuracy data for further technical developments in the field of solar energy utilization.

This paper presents the ARAD network with its aims, scopes and innovative approaches. First, Sect. 2 details the concept of ARAD, the stations network and the measurement setup. Section 3 illustrates the data processing and quality control. An uncertainty analysis, presented in Sect. 4, explores the range for the combined expanded uncertainty of all ARAD stations. In Sect. 5 the data policy, allocation and some examples of data usage are presented. Finally, Sect. 6 discusses some key points before the summary concludes the paper in Sect. 7.

As given in the Guide to the Expression of Uncertainty in Measurement (GUM) (JCGM, 2008) and in Gupta (2012) the following metrological terms are used throughout the manuscript: (1) standard uncertainty, meaning the uncertainty of a measurement result expressed as a standard de- 


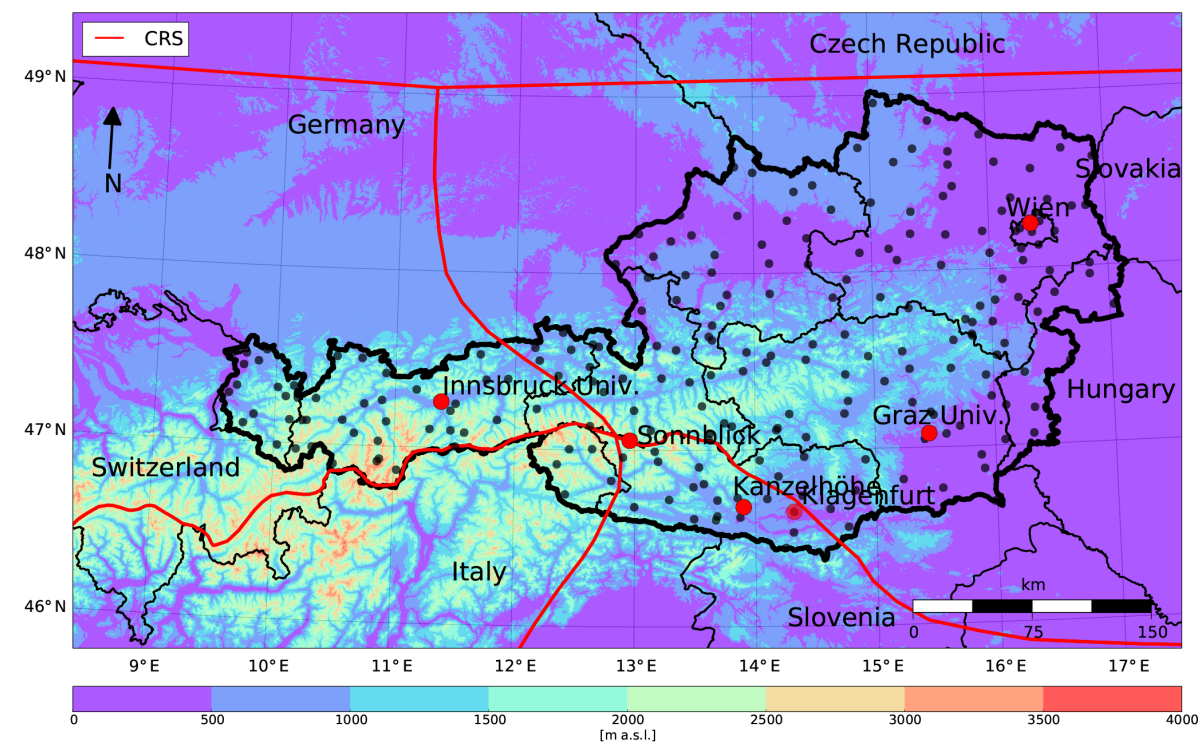

Figure 1. Topographic map (color-coded elevations) with ARAD stations (red points; the station at Klagenfurt is planned to start operating in 2016), TAWES stations measuring GLO (black points) and the coarse resolution subregions (CRSs) defined as regions with common climatic variability (see text).

viation; (2) combined standard uncertainty, like (1) but the result is obtained from the values of a number of other quantities; (3) expanded uncertainty, similar to (1) but corresponding to the $95 \%$ confidence interval; (4) coverage factor, the numerical factor used as a multiplier of the combined standard uncertainty in order to obtain an expanded uncertainty (here we are using a coverage factor of 1.96, assuming a Gaussian distribution).

\section{Concept of ARAD}

\subsection{Aims of ARAD}

The general aim of ARAD is to establish a high-accuracy long-term monitoring network for solar and terrestrial surface radiation in Austria in order to assess the status as well as the temporal and spatial changes of radiative fluxes at/to the surface. To this aim, three general principles served as the basis for establishing the ARAD network: (i) to explore the potential of existing radiation measurements, or measurements with linkage to radiation (e.g., aerosols), (ii) to continue long-term observational series of radiation with known high quality and (iii) to capture the spatial patterns of the radiation climate in Austria. Consequently, observations at five sites are routinely performed, following, as far as practicable, the guidelines for surface radiation measurements established by the BSRN (McArthur, 2005). BSRN guidelines detail the standardization of observation methods (instrument specifications, site location, measurement and calibration procedures, maintenance procedures and intervals) and data acquisition, storage and quality control. Although
ARAD stays close to BSRN guidelines, operational logistics at some sites require slight deviations from these.

The accuracy targets for BSRN irradiance measurements are (McArthur, 2005) $0.5 \%$ or $1.5 \mathrm{~W} \mathrm{~m}^{-2}$ for direct normal, $2 \%$ or $5 \mathrm{~W} \mathrm{~m}^{-2}$ for global and $2 \%$ or $3 \mathrm{~W} \mathrm{~m}^{-2}$ for diffuse and downward infrared radiation; thus measurement accuracies must always be lower than either the relative or the absolute value (whichever is larger).

\subsection{Station network}

The ARAD network comprises currently five monitoring sites: Wien Hohe Warte (WHW; $198 \mathrm{~m}$ a.s.l.), Graz/University (GRZ; 398 m a.s.l.), Innsbruck/University (IBK; 578 m a.s.1.), Kanzelhöhe (KSO; 1540 m a.s.l., since 2013) and Sonnblick (SON; 3109 m a.s.l.) which have been operating since 2011.

As can be seen in Fig. 1, ARAD covers currently four out of five so-called coarse-resolution subregions (CRSs) defined in the HISTALP project (HIstorical Instrumental climatological Surface Time series, (Auer et al., 2007). CRSs define subregions with common long-term trends for multiple climate parameters (air pressure, air temperature, precipitation, sunshine duration and cloudiness) within the GAR. There are four CRSs defined in the horizontal domain (regions: northwest, northeast, southeast, southwest) and one in the vertical domain (high-elevation summit sites). Currently all CRSs, besides the southwest region, are represented by at least one ARAD site. For comparison reasons, Fig. 1 also shows the location of the automated stations of the national meteorological observing network of Austria (semi-automatic weather 
Table 1. List of measurement instruments used at ARAD stations.

\begin{tabular}{|c|c|c|c|c|c|c|}
\hline Parameter & Manufacturer & Type & $\begin{array}{l}\text { ISO-9060 } \\
\text { classification }\end{array}$ & $\begin{array}{c}\text { Spectral } \\
\text { range }(\mathrm{nm})\end{array}$ & $\begin{array}{c}\text { Sensitivities } \\
\mathrm{min} / \mathrm{max} / \mathrm{mean} \\
\left(\mu \mathrm{VW}^{-1} \mathrm{~m}^{-2}\right)\end{array}$ & $\begin{array}{c}\text { Expanded } \\
\text { uncertainty range } \\
\min / \max / \text { mean } \\
(\%)\end{array}$ \\
\hline DIR & Kipp \& Zonen & CHP1 & first & $200-4000$ & $7.62 / 8.02 / 7.78$ & 1.1/1.1/1.1 \\
\hline DIR & Hukseflux & DR02-T & first-class & $200-4000$ & $10.05 / 11.93 / 10.97$ & $1.3 / 1.5 / 1.4$ \\
\hline GLO & Kipp \& Zonen & CMP21 & condary standard & $285-2800$ & $8.29 / 12.75 / 9.52$ & $1.4 / 1.5 / 1.5$ \\
\hline GLO & Kipp \& Zonen & CM22 & secondary standard & $200-3600$ & 9.15/9.19/9.17 & $1.0 / 1.0 / 1.0$ \\
\hline DIF & Kipp \& Zonen & CMP21 & secondary standard & $285-2800$ & $8.29 / 12.75 / 9.52$ & $1.4 / 1.5 / 1.5$ \\
\hline DIF & Kipp \& Zonen & CM22 & secondary standard & $200-3600$ & $9.15 / 9.19 / 9.17$ & $1.0 / 1.0 / 1.0$ \\
\hline DLW & Kipp \& Zonen & CGR4/CG4 & - & $4500-42000$ & $6.70 / 15.25 / 10.78$ & $1.9 / 5.6 / 4.1$ \\
\hline
\end{tabular}

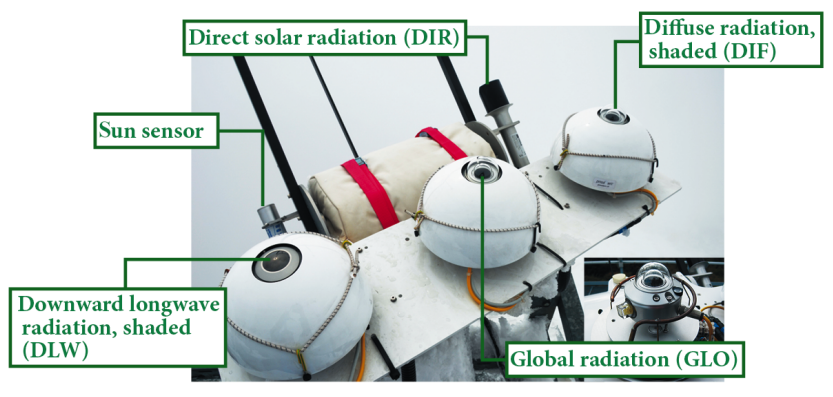

Figure 2. Typical ARAD station: suntracker with different radiation sensors. The picture in the lower right corner shows a pyranometer without radiation shield exposing the heating and ventilation system (PMOD-VHS).

stations, TAWES, operated by ZAMG) measuring global radiation by Schenk star pyranometers.

The designated ARAD site Klagenfurt (which will be operational by 2016) will provide, along with the ARAD sites KSO and SON, a unique vertical transect of radiation measurements south of the Alpine main ridge, within relatively small horizontal distance (approximately $100 \mathrm{~km}$ ) and with very similar mesoscale synoptic conditions. This transect will allow vertical gradients of radiative fluxes with and without cloud effects to be investigated, as well as effects of boundary layer dynamics and thickness, related to synoptic conditions and anthropogenic emissions, and turbidity effects on radiative fluxes.

It is important to mention that one of the ARAD sites, SON, is also included in the BSRN network (since January 2013; http://bsrn.awi.de/stations/listings.html). Due to some technical modifications (see Sect. 2.4.4) and the regular maintenance of the on-site staff, the SON station offers continuous, all-weather radiation measurements at an exposed high-alpine site $(3109 \mathrm{~m}$ a.s.l.). SON is the only radiation monitoring station that provides continuous measurements at BSRN level at such altitude in Europe. Additionally, SON is the second highest BSRN station worldwide following Station Concordia at Dome C, Antarctica (3233 m a.s.1.).

\subsection{Station setup}

ARAD sites are equipped with four broadband radiation sensors which are suitable to BSRN requirements, mounted on a suntracker (see Fig. 2), for measurements of global (GLO), direct (DIR) and diffuse (DIF) solar radiation and downward longwave radiation (DLW). The suntracker allows correct tracking of the solar path, guarantees the continuous alignment of the pyrheliometer to record DIR and ensures continuous shading of the pyranometer for measurements of DIF and the pyrgeometer for measurements of DLW. All radiation sensors used within ARAD are state-of-the-art thermopile instruments with specifications well within the limits recommended and accepted by BSRN. Following the ISO 9060 classification, all pyranometers used within ARAD are secondary standard instruments and all pyrheliometers are first-class instruments. Further details on instrument specifications can be found in Table 1 .

Within ARAD all horizontally mounted sensors are placed in ventilation units to reduce solar loading and thermal offsets; in addition they are heated and ventilated (see Fig. 2) in order to reduce interference by rain drops, dew, rime, ice and snow deposition on the instrument dome and to reduce temperature gradients that are known to occur between the glass dome and the instrument body due to infrared (IR) losses (Philipona, 2002). For ARAD pyranometers and pyrgeometers we mostly use the heating and ventilation system PMOD-VHS developed by the Physikalisch-Meteorologisches Observatorium Davos (PMOD) in Switzerland (described in detail in Philipona (2002) and the ventilation unit SBL 480 developed by the German manufacturer Eigenbrodt (see Fig. 3); however slight deviations in instrumentation occur depending on the station (see Table 2 for site-specific information). At KSO all radiometers are equipped with ventilation units CV 2 developed by manufacturer Kipp \& Zonen. For one of the pyranometers and the pyrgeometer at the ARAD GRZ station we use a slightly different, self-designed system. ARAD sensors use a general heating power of $10 \mathrm{~W}$, with the exception of 
Table 2. List of metadata of the ARAD stations. Mean annual air temperatures (Temp.) and precipitation sums (Precip.) are given for the climatological period 1981-2010.

\begin{tabular}{|c|c|c|c|c|c|}
\hline & Wien & Graz & Innsbruck & Sonnblick & Kanzelhöhe \\
\hline Lat. $\left(^{\circ}\right)$ & 48.25 & 47.08 & 47.26 & 47.05 & 46.68 \\
\hline Long. $\left(^{\circ}\right)$ & 16.36 & 15.45 & 11.38 & 12.96 & 13.90 \\
\hline Alt. (m) & 198 & 398 & 578 & 3109 & 1540 \\
\hline Temp. $\left({ }^{\circ} \mathrm{C}\right)$ & 10.4 & 9.8 & 9.4 & -5.1 & 4.6 \\
\hline Precip. (mm) & 651 & 885 & 911 & 2263 & 1103 \\
\hline Topography type & Flat/urban & Flat/urban & $\begin{array}{l}\text { Mountain } \\
\text { valley/urban }\end{array}$ & $\begin{array}{l}\text { Mountain- } \\
\text { top/rural }\end{array}$ & $\begin{array}{l}\text { Mountain- } \\
\text { top/rural }\end{array}$ \\
\hline Suntracker & Solys 2 & $2 \mathrm{AP}$ & Solys 2 & $2 \mathrm{AP}$ & Solys 2 \\
\hline Instruments & $\begin{array}{c}\text { 2xCMP21, } \\
\text { 1xCHP1, } \\
\text { 1xCGR4 }\end{array}$ & $\begin{array}{c}\text { 2xCMP21, } \\
\text { 1xCHP1, } \\
\text { 1xCGR4 }\end{array}$ & $\begin{array}{c}\text { 2xCMP21, } \\
\text { 1xCHP1, } \\
\text { 1xCGR4 }\end{array}$ & $\begin{array}{c}\text { 2xCMP21, } \\
\text { 1xDR02, } \\
\text { 1xCGR4 }\end{array}$ & $\begin{array}{c}2 \mathrm{xCM} 22, \\
1 \mathrm{XCHP} 1, \\
1 \mathrm{xCG} 4\end{array}$ \\
\hline $\begin{array}{l}\text { Heating/ } \\
\text { vent device }\end{array}$ & PMOD-VHS & $\begin{array}{l}\text { Eigenbrodt/ } \\
\text { self-designed }\end{array}$ & PMOD-VHS & Eigenbrodt & Kipp \& Zonen \\
\hline Operated by & ZAMG & ZAMG/Uni Graz & $\begin{array}{c}\text { ZAMG/ } \\
\text { Uni Innsbruck }\end{array}$ & ZAMG & KSO/ZAMG \\
\hline Monitoring start & 9 Feb 2011 & 31 Aug 2011 & 5 Jul 2011 & 1 Jan 2011 & 1 Jan 2013 \\
\hline
\end{tabular}

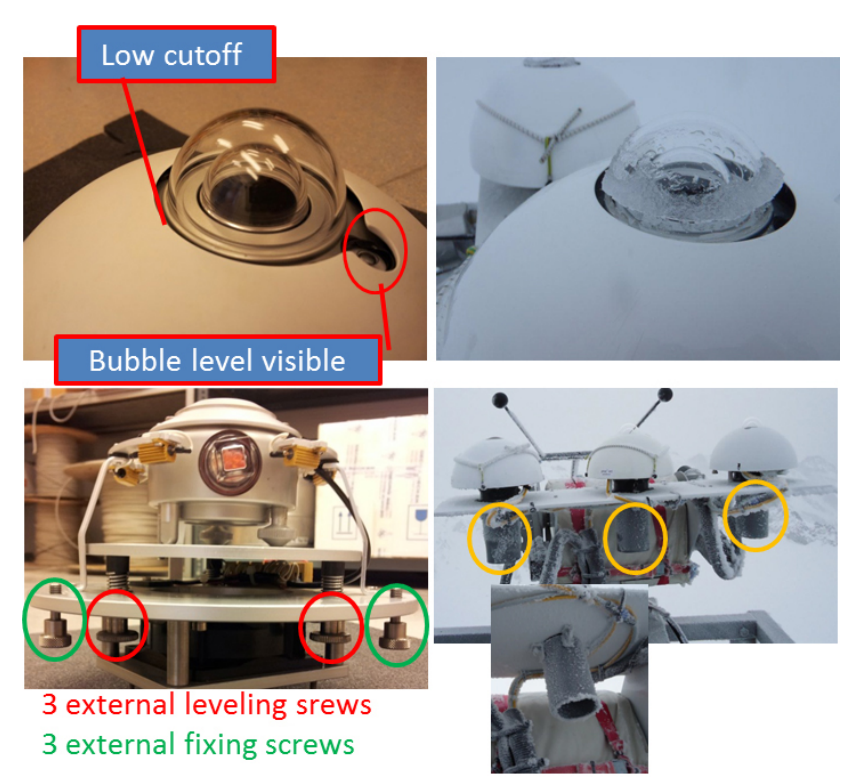

Figure 3. The modified Eigenbrodt heating and ventilation system with external sensor leveling as used for the ARAD stations (left) and some special modification to reduce snow and ice effects at ARAD/BSRN SON station: mounting plastic tubes at the inlet of the heating and ventilation system beneath the instruments (lower right) delay the buildup of rime, leading to reduced ventilation and the buildup of snow/ice on the pyranometer domes, deteriorating the radiation signal (upper right).

the SON station, where the power is increased to $25 \mathrm{~W}$ due to frequent snow and frost conditions.

A heating and ventilation system that works correctly should prevent so-called nighttime zero offsets that occur due to IR losses at the glass dome. Thus, the nighttime signal of the pyranometers is a direct quality indicator for the thermal control system. We note that the heating effect on the dome due to the fan motors is nullified when wind speeds are moderate to high.

\subsection{Measurement variables, sampling rates, data acquisition and instrument maintenance}

\subsubsection{Calibration of ARAD instruments}

ARAD pyranometers are calibrated through comparison with the working standard pyranometer (International Organization for Standardization, 1992) at ZAMG headquarters in Vienna or sent for calibration to the instrument manufacturer Kipp \& Zonen. The calibration procedure at ZAMG is based on the direct comparison of 1 min average values (with a sampling rate of $1 \mathrm{~Hz}$ ) during periods with GLO exceeding $600 \mathrm{~W} \mathrm{~m}^{-2}$ between 09:00 and 13:00 UTC. The Kipp \& Zonen indoor calibration procedure is based on a side-by-side comparison with a reference pyranometer fed by an artificial sun. To ensure continuous measurements at all ARAD stations, instruments undergoing calibration are immediately substituted by calibrated sensors of the same manufacturing type.

The working standard of ZAMG itself is calibrated using the traditional so-called sun-and-shade calibration method (International Organization for Standardization, 1993), thereby the working standard is calibrated against a cavity radiometer at ZAMG headquarters in Vienna (TMI, serial number 68025) that participates in the international pyrheliometer comparison (IPC) exercise in Davos, Switzerland, every 5 years. This procedure ensures that the reference TMI cavity radiometer is traceable to the World Radiometric Reference (WRR) in Davos, Switzerland (Fröhlich, 1991). 
It is important to note that this procedure differs from BSRN suggestions for pyranometer calibration, which recommend the "alternate method" of Forgan (1996). The Forgan method is based on swapping both pyranometers that measure GLO and DIF and calculate the calibration coefficients, based on simultaneous equations of GLO given by the component sum of DIF and DIR, before and after the swap, for specific solar zenith angles. BSRN recommends this procedure as it allows for on-site instrument calibration and avoids thermal shocks of the instrument that may occur when using the traditional sun-and-shade method (Forgan, 1996).

Despite this recommendation the ARAD consortium utilizes the sun-and-shade method for instrument calibration because (i) this approach is also used for calibration of Schenk star pyranometers at TAWES sites of ZAMG and thus provides traceability of all ZAMG radiation sensors to one common standard; (ii) it avoids the use of a traveling-standard pyrheliometer at all sites, which would be necessary when using the Forgan method; (iii) extended comparison intervals under stable clear-sky conditions are used for calibrating the reference pyranometer.

For pyrgeometers, optimal methods of calibration and traceability to an absolute irradiance scale are still under debate (Gröbner et al., 2014, 2015; Philipona, 2015). Thus, BSRN recommends sending pyrgeometers to PMOD Davos for calibration with a blackbody cavity (McArthur, 2005). Every 2 years, ARAD pyrgeometers are sent to Kipp \& Zonen for calibration. The calibration procedure is traceable to the World Infrared Standard Group (WISG) in Davos consisting of four reference pyrgeometers, building a long-term stable reference (Gröbner et al., 2014). This calibration procedure avoids the necessity of a site reference instrument because each pyrgeometer is directly traceable to WISG.

Finally, all ARAD pyrheliometers are calibrated by direct comparison (International Organization for Standardization, 1990) against a TMI cavity radiometer (participating regularly at the IPC in Davos) and thus directly traceable to the World Radiometric Reference (WRR).

At BSRN/ARAD site SON, the calibration of all instruments is performed annually, as recommended by BSRN. At other ARAD sites instrument calibration is performed every 2 years. Long-term stability analysis of ARAD radiometer sensitivities (based on different calibration certificates of the same instrument at different times) indicates that the relative change of the calibration factor over 2 years is well below $1 \%$ for all pyranometers and $<0.2 \%$ for all pyrheliometers which operate within the ARAD network.

\subsubsection{Measurements}

The radiation components GLO, DIR, DIF and DLW are the key variables measured at each ARAD site. Besides these radiation components, data on body temperature of all sensors
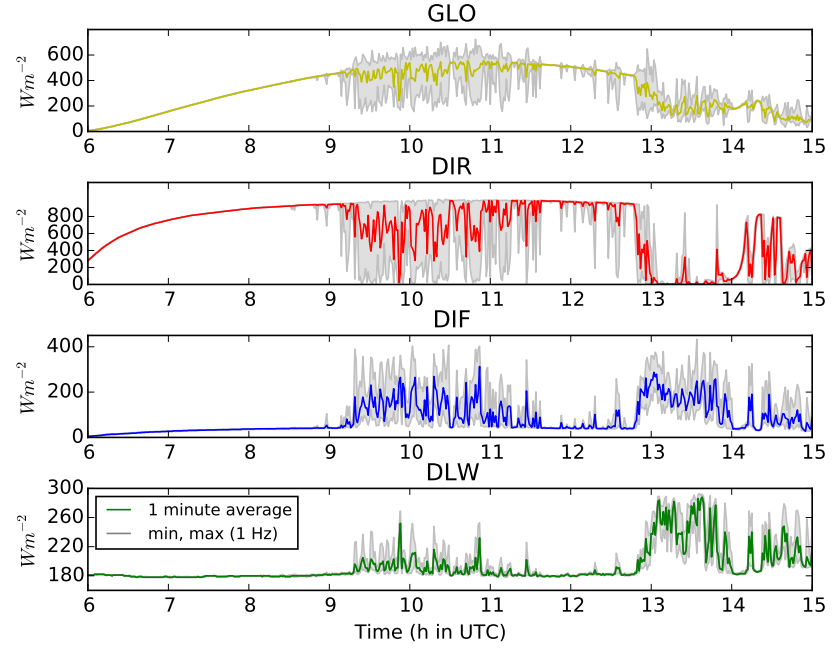

Figure 4. Sample of ARAD data measured at the SON station on 3 November 2014 between 06:00 and 15:00 UTC. GLO denotes the global radiation on a horizontal plane, DIR the direct solar radiation on a plane normal to the direct beam, DIF the diffuse radiation on a horizontal plane and DLW the downward longwave radiation.

and the heating power and ventilation of pyranometers are recorded at all ARAD sites except KSO.

Data sampling takes place at $1 \mathrm{~Hz}$ (GRZ, IBK, SON, WHW) and $10 \mathrm{~Hz}$ frequency (KSO) with the following $1 \mathrm{~min}$ statistics calculated and stored: average, standard deviation, minimum and maximum. An example plot of the measured irradiances at the SON station during 1 day is shown in Fig. 4.

A specific data acquisition system (DAQ), developed by Logotronic (http://www.logotronic.at/), is used at all ARAD sites except KSO. The DAQ is calibrated over the entire voltage range with a resolution of $10 \mu \mathrm{V}$. The accuracy of the voltage measurement from the data acquisition and logging system equals $\pm 10 \mu \mathrm{V}$, which corresponds to roughly 0.8 to $1.4 \mathrm{~W} \mathrm{~m}^{-2}$ (given the range of calibration factors of radiometers within the ARAD network, see Table 1). The ARAD site KSO uses an upper tier data logger system from Campbell Scientific (http://www.campbellsci.com) with an analog input accuracy of $\pm 0.07 \%$ plus an offset of $2.005 \mu \mathrm{V}$ and a resolution of $0.33 \mu \mathrm{V}$ for operations. Over the next years changes in the DAQ of all sites except KSO are planned to increase the resolution and accuracy of the voltage measurement.

A traceable reference voltage generator (RVG) is used to recalibrate the DAQ at all ARAD stations periodically (every 2 years). Results from RVG measurements suggest that a potential zero offset is $\langle 10 \mu \mathrm{V}$ and thus smaller than the accuracy of the acquisition system. Additional quality assurance is provided by the nighttime pyrheliometer measurements, which should not suffer from possible thermal offsets. These data show no negative radiation signals and thus provide independent confidence in the voltage measurement of 
the DAQ. The temperature dependence of the DAQ relative to the reference temperature during calibration with the RVG equals $0.4 \mu \mathrm{V}^{\circ} \mathrm{C}^{-1}$ at all stations except KSO. At the latter the temperature dependence is already corrected during logging.

Complementary to ARAD radiation data, basic meteorological records of air temperature, air pressure, relative humidity, precipitation, sunshine duration, wind speed and direction and global radiation (measured with a black and white pyranometer, a Schenk star pyranometer) from the collocated TAWES station are also stored as 1 min averages or sums in the same database. For details on meteorological observation methods and related uncertainties the interested reader is referred to Haiden et al. (2011).

\subsubsection{Instrument maintenance}

ARAD instruments are regularly inspected and maintained by human observers. Maintenance intervals are at a maximum 1 week within the ARAD network. At three sites, the BSRN site SON, KSO and GRZ instruments are maintained on a daily basis, as recommended by BSRN.

Maintenance tasks are defined corresponding to BSRN standards, are regulated in a maintenance manual and follow a defined number of checks. These include (i) cleaning and verifying leveling of all instruments, (ii) visually inspecting cables, ventilation and heating devices and (iii) controlling the sun tracking system and shading of the instruments recording DIF and DLW. Immediately after maintenance, the results of the check are entered in a web interface and stored in a central database for further processing and use. On an annual or biennial basis the heating and ventilation systems are cleaned and a control and service of the sun tracking system is performed following recommendations by the manufacturer. Apart from these routine and regular maintenance tasks, occasional service is required whenever failed checks recorded by a human observer or the automated or manual data quality analysis (see Sect. 3.2) make this necessary.

\subsubsection{Special configurations at BSRN site SON}

The harsh weather conditions at the ARAD and BSRN station SON required the following technical adaptations: (1) for data quality assurance the heating and ventilation power of a pyranometer or pyrgeometer (see Sect. 2.3) is connected to one single electrical circuit per instrument. In case of a single failure of the ventilation (due to e.g., ice formation) the heater is also immediately turned off, avoiding differential heating leading to additional thermal offsets. (2) Before operational use of the Hukseflux DR02-T pyrheliometer with a heated front window, different shading and heating experiments were performed to determine the ideal heating power between maximum frost removal efficiency and minimum thermal offsets, which was found to be $2.1 \mathrm{~W}$. A comparison of DIR using the heated DR02-T (cor- rected with temperature dependence) and an unheated CHP1 pyrheliometer over 11 clear-sky days during a 2-year period showed a mean relative difference of $-2.0 \%( \pm 0.18 \%$ expanded uncertainty). This is well within the differences found between different pyrheliometers of the same type when compared to open cavity radiometers in an extensive pyrheliometer intercomparison exercise (Michalsky et al., 2011). (3) At the SON station we use heating and ventilation devices produced by the German manufacturer Eigenbrodt. The radiation shield of these devices are lowered a little to reduce cutoffs during sunrise and sunset. Further, the systems offer a fixing system of the radiation shield that is easier to handle and an external leveling system with bigger screws mounted from below (see Fig. 3). (4) To reduce instrument problems at the SON station due to frost and ice, we mounted plastic tubes, $0.2 \mathrm{~m}$ long and $0.05 \mathrm{~m}$ wide, to the inlets of the heating and ventilation system beneath the pyranometers and pyrgeometers, replacing the grid that usually protects the instruments from insects, large aerosols and pollen, as these do not pose a problem at high elevations. This modification has proven to effectively delay the buildup of rime that could otherwise easily become thick enough to disturb and reduce the ventilation and thus the heating effect on the glass dome, leading to rime formation on the domes and attenuation of any irradiance signal (see Fig. 3).

\section{Data}

\subsection{Operational data processing}

After being measured and recorded, all parameters (see Sect. 2.4.2), are immediately stored in a Sybase database at ZAMG in Vienna. The ARAD convention is thereby to store both the raw voltage output signal of the sensors and the irradiance in $\mathrm{W} \mathrm{m}^{-2}$ converted from the raw signal using the individual calibration factor of the instrument. We note that currently no automated correction of the calibration factor for temperature effects is applied for most ARAD sensors (those provided by Kipp \& Zonen) as such correction is considered negligible (well within $\pm 0.5 \%$ between -20 and $+50^{\circ} \mathrm{C}$ relative to $+20^{\circ} \mathrm{C}$ ).

One exception in this respect is the front-window heated Hukseflux DR02-T pyrheliometer operated at SON. For this instrument, temperature effects are not negligible (estimated as $5 \%$ at $-30^{\circ} \mathrm{C}$ ), and an individual correction polynomial provided by the manufacturer is applied before data transmission to the ARAD database (or the BSRN archive or other customers).

\subsection{Quality control}

To maximize ARAD data quality we use a combination of a manual and two automated data quality control (QC) methods with daily and hourly resolution (weekend data are controlled at the beginning of the following week). The algo- 
Table 3. Summary of the quality flag statistics (average of 2012-2014) for the measured parameters GLO, DIF, DIR, DLW at four ARAD sites which have been operating since 2012 using the combined daily automated and manual QC including e.g., maintenance times. The last row ("Perfect") indicates the percentage of timestamps when all four parameters are simultaneously flagged as "good".

\begin{tabular}{lcccc}
\hline Flag & Wien $(\%)$ & Graz $(\%)$ & Innsbruck $(\%)$ & Sonnblick $(\%)$ \\
\hline & GLO, DIF, DIR, DLW & GLO, DIF, DIR, DLW & GLO, DIF, DIR, DLW & GLO, DIF, DIR, DLW \\
Good (1) & $99 / 98 / 98 / 96$ & $93 / 96 / 96 / 95$ & $92 / 93 / 94 / 91$ & $81 / 74 / 85 / 81$ \\
Wrong (2) & $1 / 1 / 0 / 0$ & $6 / 3 / 2 / 2$ & $1 / 1 / 0 / 0$ & $16 / 24 / 13 / 14$ \\
Dubious (3) & $0 / 0 / 1 / 3$ & $0 / 1 / 1 / 3$ & $0 / 0 / 0 / 3$ & $1 / 1 / 1 / 3$ \\
Missing (255) & $1 / 0 / 0 / 0$ & $1 / 1 / 1 / 1$ & $5 / 5 / 5 / 5$ & $1 / 1 / 1 / 1$ \\
"Perfect" & 94 & 88 & 89 & 67 \\
\hline
\end{tabular}

rithms used for automated control are an extended version of those provided by Long and Shi (2008); see details below.

\subsubsection{Manual quality control}

The daily manual data QC consists of visual inspections of (i) the graph of the daily automated QC (see Sect. 3.2.2) from the previous day, (ii) a near-real time, interactive data plot of all stations (updated every $5 \mathrm{~min}$ ) of the $1 \mathrm{~min}$ average radiation values and DIR calculated on the horizontal surface to enable the comparison between GLO and its component sum (DIR + DIF), (iii) review of automated e-mail alerts sent by the hourly QC (see Sect. 3.2.3).

\subsubsection{Automated quality control}

The daily automated QC consists of a script containing the QC criteria for all recorded radiation fluxes as described in Long and Shi (2008) as well as some additional criteria detailed below. The automated script is run daily for the data recorded over the last $24 \mathrm{~h}$ at all ARAD stations. For each station, the script reads a metadata file containing all relevant coefficients for criteria that have been established based on site specific data (e.g., upper climatological limits of fluxes as in Long and Shi, 2008).

In an initial step the automated QC creates quality flags for each recorded element and the records are modified from their initial value 0 (unchecked data) to either one of the following four states: 1 (data checked and passed all tests successfully), 2 (data checked but wrong as at least one test failed), 3 (data checked but of questionable quality), 255 (missing data) and stored in separate tables of the database.

In a second step a graphical summary of the daily automated QC is produced. This graph shows the time series of the $1 \mathrm{~min}$ averaged radiation fluxes along with the cloud observations from the hourly SYNOP report from the closest available station and information about failed QC criteria from the automated QC as detailed below.

A third step in the QC procedure comprises the checking of 61 quality criteria. These criteria can be grouped into four types: (1) integrity tests (e.g., missing values), (2) outlier detections, (3) $\mathrm{min} / \mathrm{max}$ tests (e.g., exceedance of possible limits) and (4) comparison tests (e.g., GLO vs. component sum of DIR horizontal + DIF). For further details on these quality tests the reader is referred to the work of Long and Shi (2008). During this QC process, two tables are created in the database per site, containing the station-specific coefficients needed for the automated QC and the daily summaries for errors that occurred during the check of 61 quality criteria.

Finally measured irradiance signals are converted to units of $\mathrm{W} \mathrm{m}^{-2}$ using instrument-specific calibration factors stored in a separate database table. Furthermore, irradiance solar position (azimuth and zenith) and the clear-sky index (Marty and Philipona, 2000) are stored in this database table. The clear-sky index is used to separate clear-sky from cloudy days in further analysis.

Table 3 summarizes the 3-year average quality flag statistics for all stations which have been operating since 2012 . The fraction of data flagged as good equals, depending on the measured parameter, $74-85 \%$ at SON and $91-99 \%$ at the other stations. Note, that reduced values at the GRZ station compared to WHW and IBK do not reflect a lower quality but more frequent daily maintenance (data are flagged as "wrong" during maintenance). The fraction of observations where data of all four parameters are simultaneously flagged as "good" ranges from $67 \%$ at the SON to $88-94 \%$ at other ARAD stations. Lower data quality at the BSRN SON station reflects the difficult measurement conditions at this exposed high-alpine site.

\subsubsection{Hourly automated quality control}

The hourly automated QC consists essentially of a strongly reduced set of criteria from the daily automated QC, and no quality flags are recorded in a database; instead, an email containing the error information is sent to the on-site staff in case of failure of any QC criteria. Hourly checked criteria consist of all tests described in Appendix A plus a check for missing data. The outlier detection (test (4) in Appendix A) is thereby not applied to the irradiance signals as during the daily automated QC but to the difference between instrument housing temperature and air temperature to detect eventual thermal offsets. 
Table 4. Contributions to uncertainties affecting shortwave measurements at all five ARAD stations in the period 1 July 2014 to 30 June 2015.

\begin{tabular}{|c|c|c|c|c|c|c|c|c|c|c|}
\hline & & & Expanded & & & & & Standard $^{\mathrm{a}}$ & & \\
\hline & WHW & GRZ & IBK & KSO & SON & WHW & GRZ & IBK & KSO & SON \\
\hline \multicolumn{11}{|c|}{ Sensitivity factor $\left(u_{\mathrm{S}}\right)$} \\
\hline DIR & $1.28 \%$ & $1.28 \%$ & $1.28 \%$ & $1.49 \%$ & $1.53 \%$ & $0.65 \%$ & $0.65 \%$ & $0.65 \%$ & $0.76 \%$ & $0.78 \%$ \\
\hline GLO & $1.90 \%$ & $1.98 \%$ & $1.98 \%$ & $2.55 \%$ & $1.53 \%$ & $0.97 \%$ & $1.01 \%$ & $1.01 \%$ & $1.30 \%$ & $0.78 \%$ \\
\hline DIF & $1.90 \%$ & $1.90 \%$ & $1.97 \%$ & $2.55 \%$ & $1.53 \%$ & $0.97 \%$ & $0.97 \%$ & $1.01 \%$ & $1.30 \%$ & $0.78 \%$ \\
\hline \multicolumn{11}{|c|}{ Uncertainty of the raw signal U/of the DAQ $\left(u_{u}\right)$} \\
\hline DIR & $10 \mu \mathrm{V}$ & $10 \mu \mathrm{V}$ & $10 \mu \mathrm{V}$ & $\begin{array}{l}0.07 \% \\
+2 \mu \mathrm{V}\end{array}$ & $10 \mu \mathrm{V}$ & $5.77 \mu \mathrm{V}$ & $5.77 \mu \mathrm{V}$ & $5.77 \mu \mathrm{V}$ & $\begin{array}{c}0.04 \% \\
+1.15 \mu \mathrm{V}\end{array}$ & $5.77 \mu \mathrm{V}$ \\
\hline GLO & $10 \mu \mathrm{V}$ & $10 \mu \mathrm{V}$ & $10 \mu \mathrm{V}$ & $\begin{array}{l}0.07 \% \\
+2 \mu \mathrm{V}\end{array}$ & $10 \mu \mathrm{V}$ & $5.77 \mu \mathrm{V}$ & $5.77 \mu \mathrm{V}$ & $5.77 \mu \mathrm{V}$ & $\begin{array}{c}0.04 \% \\
+1.15 \mu \mathrm{V}\end{array}$ & $5.77 \mu \mathrm{V}$ \\
\hline DIF & $10 \mu \mathrm{V}$ & $10 \mu \mathrm{V}$ & $10 \mu \mathrm{V}$ & $\begin{array}{l}0.07 \% \\
+2 \mu \mathrm{V}\end{array}$ & $10 \mu \mathrm{V}$ & $5.77 \mu \mathrm{V}$ & $5.77 \mu \mathrm{V}$ & $5.77 \mu \mathrm{V}$ & $\begin{array}{c}0.04 \% \\
+1.15 \mu \mathrm{V}\end{array}$ & $5.77 \mu \mathrm{V}$ \\
\hline \multicolumn{11}{|c|}{ Statistical uncertainty $\left(u_{\text {stat }}\right)$} \\
\hline DIR & & & & & & $0.37 \%$ & $0.29 \%$ & $0.22 \%$ & $0.25 \%$ & $0.29 \%$ \\
\hline GLO & & & & & & $0.33 \%$ & $0.29 \%$ & $0.22 \%$ & $0.3 \%$ & $0.4 \%$ \\
\hline DIF & & & & & & $0.23 \%$ & $0.21 \%$ & $0.15 \%$ & $0.62 \%$ & $1.1 \%$ \\
\hline \multicolumn{11}{|c|}{$\begin{array}{c}\text { Operational uncertainties }\left(u_{\mathrm{op}}\right) \\
\text { 1. Thermal effect }\end{array}$} \\
\hline GLO & 0 & $2 \mathrm{~W} \mathrm{~m}^{-2}$ & $1 \mathrm{~W} \mathrm{~m}^{-2}$ & $1 \mathrm{Wm}^{-2}$ & $1 \mathrm{Wm}^{-2}$ & 0 & $1.02 \mathrm{~W} \mathrm{~m}^{-2}$ & $0.51 \mathrm{Wm}^{-2}$ & $0.51 \mathrm{Wm}^{-2}$ & $0.51 \mathrm{Wm}^{-2}$ \\
\hline DIF & $1 \mathrm{Wm}^{-2}$ & 0 & $1 \mathrm{Wm}^{-2}$ & $1 \mathrm{~W} \mathrm{~m}^{-2}$ & $1 \mathrm{~W} \mathrm{~m}^{-2}$ & $0.51 \mathrm{~W} \mathrm{~m}^{-2}$ & 0 & $0.51 \mathrm{Wm}^{-2}$ & $0.51 \mathrm{Wm}^{-2}$ & $0.51 \mathrm{Wm}^{-2}$ \\
\hline \multicolumn{11}{|c|}{ 2. Directional error } \\
\hline GLO & $10 \mathrm{Wm}^{-2}$ & $10 \mathrm{~W} \mathrm{~m}^{-2}$ & $10 \mathrm{Wm}^{-2}$ & $5 \mathrm{~W} \mathrm{~m}^{-2}$ & $10 \mathrm{~W} \mathrm{~m}^{-2}$ & $5.77 \mathrm{~W} \mathrm{~m}^{-2}$ & $5.77 \mathrm{Wm}^{-2}$ & $5.77 \mathrm{Wm}^{-2}$ & $2.89 \mathrm{Wm}^{-2}$ & $5.77 \mathrm{~W} \mathrm{~m}^{-2}$ \\
\hline \multicolumn{11}{|c|}{ 3. Soiling } \\
\hline DIR & $0.8 \%$ & $0.4 \%$ & $1.0 \%$ & $0.3 \%$ & $0.2 \%$ & $0.41 \%$ & $0.2 \%$ & $0.51 \%$ & $0.15 \%$ & $0.1 \%$ \\
\hline \multicolumn{11}{|c|}{ 4. Leveling } \\
\hline GLO & $0.76 \%$ & $0.8 \%$ & $0.91 \%$ & $1.02 \%$ & $0.9 \%$ & $0.39 \%$ & $0.41 \%$ & $0.46 \%$ & $0.52 \%$ & $0.46 \%$ \\
\hline
\end{tabular}

\section{Uncertainty analysis of ARAD observations}

In the following paragraphs we detail uncertainty estimates for all shortwave radiative fluxes measured at all five ARAD sites over the full annual cycle from 1 July 2014 to 30 June 2015.

\subsection{Shortwave fluxes}

The measurement equation for the shortwave fluxes (GLO, DIF and DIR) reads

$I_{c}=\frac{U}{S_{c}}$,

where $I_{c}$ is the irradiance in $\mathrm{W} \mathrm{m}^{-2}, U$ is the raw signal (voltage) and $S_{c}$ is the sensitivity given in $\mu \mathrm{V}\left(\mathrm{W} \mathrm{m}^{-2}\right)$. The combined standard uncertainty $U_{i}$ of the measured irradiance $I_{c}$ is then, following Vuilleumier et al. (2014),

$U_{i}=\sqrt{\frac{u_{s}^{2} U^{2}}{S_{c}^{4}}+\frac{u_{u}^{2}}{S_{c}^{2}}+u_{\mathrm{stat}}^{2}+u_{\mathrm{os}}^{2} \sum u_{\mathrm{op}}^{2}}$

where $u_{s}$ and $u_{u}$ are the standard uncertainties (Reda, 2011) of the sensitivity and the raw signal, respectively. The term $u_{\text {stat }}$ is calculated following Vuilleumier et al. (2014) from the standard deviation of the $1 \mathrm{~Hz}$ irradiance data (with quality flag 1), measured during 1 min intervals, at times when
DIR is slowly varying. $u_{\mathrm{os}}$ is a correction factor compensating a potential offset due to a thermal effect (note: this applies only to pyranometer measurements). Finally, $u_{\text {op }}$ are operational uncertainties such as e.g., leveling, soiling or directional response that can affect either $S_{c}$ or $U$ and depend on the measured irradiance quantity. As these uncertainties are expected to be proportional to the measured signal, the final combined uncertainties are expressed separately for a small $\left(50 \mathrm{~W} \mathrm{~m}^{-2}\right)$ and a large $\left(1000 \mathrm{~W} \mathrm{~m}^{-2}\right.$ (GLO, DIR) and $500 \mathrm{~W} \mathrm{~m}^{-2}$, DIF) signal, following the methodology by Vuilleumier et al. (2014).

The first term $\frac{u_{s}^{2} U^{2}}{S_{c}^{4}} \frac{u_{s}^{2} U^{2}}{S_{c}^{4}}$ in Eq. (2) describes the uncertainty of the sensitivity. To derive the standard uncertainty of the sensitivity $u_{s}$ the square root of the quadratic sum of the calibration uncertainty, provided for each instrument by the manufacturer, and other uncertainties provided by the manufacturer (e.g., nonlinearity, temperature dependence and aging) need to be taken into account. As those values are provided as expanded uncertainties, they need to be converted into standard uncertainties, i.e., by dividing them by the coverage factor (1.96 in the case of the calibration uncertainty, assuming a Gaussian distribution and $\sqrt{3}$ in the case of the other three terms assuming a rectangular distribution; Reda, 2011). Results for shortwave instruments at ARAD sites are shown in Tables 4-6. 
Table 5. Same as Table 4 but relative contributions of uncertainty components to total combined uncertainty. Uncertainties are given for a small (ss: $50 \mathrm{~W} \mathrm{~m}^{-2}$ ) and a large (1s: $500 \mathrm{~W} \mathrm{~m}^{-2}$ for DIF and $1000 \mathrm{~W} \mathrm{~m}^{-2}$ for DIR and GLO) signal.

\begin{tabular}{|c|c|c|c|c|c|c|c|c|c|c|}
\hline & \multicolumn{10}{|c|}{ Contribution $(\%)^{\mathrm{a}}$} \\
\hline & WHW & GRZ & $\begin{array}{l}\text { ss } \\
\text { IBK }\end{array}$ & $\mathrm{KSO}$ & SON & WHW & GRZ & $\begin{array}{l}\text { ls } \\
\text { IBK }\end{array}$ & $\mathrm{KSO}$ & SON \\
\hline \multicolumn{11}{|c|}{ Sensitivity factor $\left(u_{\mathrm{S}}\right)$} \\
\hline DIR & 15 & 14 & 10 & $74^{\mathrm{b}}$ & 34 & $58^{\mathrm{b}}$ & $76^{\mathrm{b}}$ & $57^{\mathrm{b}}$ & $87^{\mathrm{b}}$ & $86^{\mathrm{b}}$ \\
\hline GLO & 1 & 1 & 1 & 5 & 0 & $61^{\mathrm{b}}$ & $63^{b}$ & $63^{\mathrm{b}}$ & $79^{b}$ & $46^{\mathrm{b}}$ \\
\hline DIF & 24 & 29 & 21 & $53^{\mathrm{b}}$ & 17 & $92^{\mathrm{b}}$ & $93^{b}$ & $94^{\mathrm{b}}$ & $81^{\mathrm{b}}$ & 33 \\
\hline \multicolumn{11}{|c|}{ Uncertainty of the raw signal U/of the DAQ $\left(u_{u}\right)$} \\
\hline DIR & $75^{\mathrm{b}}$ & $82^{\mathrm{b}}$ & $83^{\mathrm{b}}$ & 15 & $61^{\mathrm{b}}$ & 1 & 1 & 1 & $\approx 0$ & 0 \\
\hline GLO & 1 & 1 & 2 & 0 & 1 & $\approx 0$ & $\approx 0$ & $\approx 0$ & $\approx 0$ & 0 \\
\hline DIF & $48^{\mathrm{b}}$ & $70^{\mathrm{b}}$ & $56^{\mathrm{b}}$ & 3 & $50^{\mathrm{b}}$ & 2 & 2 & 2 & $\approx 0$ & 1 \\
\hline \multicolumn{11}{|c|}{ Statistical uncertainty $\left(u_{\text {stat }}\right)$} \\
\hline DIR & 5 & 3 & 1 & 8 & 5 & 19 & 15 & 7 & 9 & 12 \\
\hline GLO & $\approx 0$ & $\approx 0$ & $\approx 0$ & $\approx 0$ & 0 & 7 & 5 & 3 & 4 & 12 \\
\hline DIF & 1 & 1 & $\approx 0$ & 12 & 33 & 5 & 4 & 2 & 18 & $66^{\mathrm{b}}$ \\
\hline \multicolumn{11}{|c|}{$\begin{array}{c}\text { Operational uncertainties }\left(u_{\mathrm{op}}\right) \\
1 . \text { Thermal effect }\end{array}$} \\
\hline GLO & 0 & 3 & 1 & 3 & 1 & 0 & 1 & 0 & 0 & 0 \\
\hline DIF & 27 & 0 & 22 & 33 & 0 & 1 & 0 & 1 & 0 & 0 \\
\hline \multicolumn{11}{|c|}{ 2. Directional error } \\
\hline GLO & $98^{\mathrm{b}}$ & $95^{\mathrm{b}}$ & $96^{\mathrm{b}}$ & $91^{\mathrm{b}}$ & $97^{\mathrm{b}}$ & 22 & 21 & 21 & 4 & 25 \\
\hline \multicolumn{11}{|c|}{ 3. Soiling } \\
\hline DIR & 6 & 1 & 6 & 3 & 1 & 23 & 7 & 35 & 4 & 1 \\
\hline \multicolumn{11}{|c|}{ 4. Leveling } \\
\hline GLO & $\approx 0$ & $\approx 0$ & 0 & 1 & 0 & 10 & 10 & 13 & 13 & 16 \\
\hline
\end{tabular}

The measurement uncertainty of the raw signal $U$ is defined by the second term $\frac{u_{u}^{2}}{S_{c}^{2}}$ in Eq. (2). As described in Sect. 2.4.2, the accuracy of the voltage measurement is $\pm 10 \mu \mathrm{V}$ at all ARAD stations, except $\mathrm{KSO}$, and is nonproportional to the voltage signal. At the KSO site the accuracy of the voltage measurement is proportional to the voltage signal and equals $0.07 \%$ of the reading plus $2.005 \mu \mathrm{V}$. Following Vuilleumier et al. (2014) its distribution is assumed to be rectangular, so both accuracies have to be divided by $\sqrt{3}$ to obtain the standard uncertainties, $u_{u}=5.8 \mu \mathrm{V}$ at sites WHW, SON, IBK and GRZ and $u_{u}=$ $\pm 0.04 \%+1.15 \mu \mathrm{V}$ at the KSO site. These uncertainties together with the respective instrument sensitivities are then used to calculate the second term of Eq. (2). The results for all five ARAD sites are shown in Tables 4-6.

The third term in Eq. (2) $u_{\text {stat }}$ is derived from the standard deviation of the $1 \mathrm{~Hz}$ signal of the individual irradiance quantities at times when DIR is slowly varying. The results are given in Tables 4-6 for all ARAD sites.

The estimation of the thermal offset uncertainty $u_{\text {os }}$ (fourth term in Eq. 2) is more complicated; guidance on its (more or less intrusive) direct measurement during daytime (Bush et al., 2000; Dutton et al., 2001; Ji and Tsay, 2010; Michal- sky, 2005; Philipona, 2002), as well as its correction using other measured variables (Dutton et al., 2001; Haeffelin et al., 2001; Sanchez et al., 2015), is provided in previous studies. A recent study by Sanchez et al. (2015) concludes, based on capping experiments, that observed daytime thermal offsets, for both global and diffuse measurements, are highest correlated with the diffuse fraction of the incoming solar irradiance. These authors highlight, in agreement with earlier work by Dutton et al. (2001), the correlation with the ambient air temperature as well as with the net IR signal from a collocated pyrgeometer.

To date no routine measurement of the pyrgeometer dome temperatures nor capping experiments are available for ARAD sites. However, the latter are intended for a field campaign in 2016. Thus the detection of (daytime) thermal offsets is limited to the analysis of nighttime pyranometer data, as deviations from zero are assumed to be triggered by thermal offsets (Michalsky, 2005; Philipona, 2002). Unfortunately, the limited resolution and accuracy of the DAQ at most ARAD sites except KSO (see Sect. 2.4.2), corresponding to approximately $1 \mathrm{~W} \mathrm{~m}^{-2}$ depending on the sensitivity of the instrument, does not allow a reasonable correlation analysis between the nighttime offsets and other variables 
Table 6. Same as Tables 4 and 5 but products of sensitivity factor $c_{i}$ and standard uncertainty $u_{i}$. Numbers are given for a small (ss: $50 \mathrm{~W} \mathrm{~m}^{-2}$ ) and a large (1s: $500 \mathrm{~W} \mathrm{~m}^{-2}$ for DIF and $1000 \mathrm{~W} \mathrm{~m}^{-2}$ for DIR and GLO) signal.

\begin{tabular}{|c|c|c|c|c|c|c|c|c|c|c|}
\hline & \multicolumn{10}{|c|}{$\mathrm{c}_{i}^{2} u_{i}^{2}\left(\mathrm{~W}^{2} \mathrm{~m}^{-4}\right)$} \\
\hline & WHW & GRZ & $\begin{array}{l}\text { ss } \\
\text { IBK }\end{array}$ & KSO & SON & WHW & GRZ & $\begin{array}{l}\text { ls } \\
\text { IBK }\end{array}$ & KSO & $\mathrm{SON}$ \\
\hline \multicolumn{11}{|c|}{ Sensitivity factor $\left(u_{\mathrm{S}}\right)$} \\
\hline DIR & 0.1 & 0.1 & 0.1 & 0.1 & 0.2 & 42.5 & 42.5 & 42.5 & 57.5 & 60.7 \\
\hline GLO & 0.2 & 0.3 & 0.3 & 0.4 & 0.2 & 94.0 & 101.6 & 101.6 & 169.0 & 60.7 \\
\hline DIF & 0.2 & 0.2 & 0.3 & 0.4 & 0.2 & 23.5 & 23.5 & 25.4 & 42.3 & 15.2 \\
\hline \multicolumn{11}{|c|}{ Uncertainty of the raw signal $U /$ of the DAQ $\left(u_{u}\right)$} \\
\hline DIR & 0.5 & 0.7 & 0.9 & $\approx 0$ & 0.3 & 0.5 & 0.7 & 0.9 & 0.3 & 0.3 \\
\hline GLO & 0.4 & 0.5 & 0.6 & $\approx 0$ & 0.5 & 0.4 & 0.5 & 0.6 & 0.3 & 0.5 \\
\hline DIF & 0.5 & 0.6 & 0.7 & $\approx 0$ & 0.5 & 0.5 & 0.6 & 0.7 & 0.1 & 0.5 \\
\hline \multicolumn{11}{|c|}{ Statistical uncertainty $\left(u_{\text {stat }}\right)$} \\
\hline DIR & $\approx 0$ & $\approx 0$ & $\approx 0$ & $\approx 0$ & $\approx 0$ & 13.7 & 8.4 & 4.8 & 6.3 & 8.4 \\
\hline GLO & $\approx 0$ & $\approx 0$ & $\approx 0$ & $\approx 0$ & $\approx 0$ & 10.9 & 8.4 & 4.8 & 9.0 & 16.0 \\
\hline DIF & $\approx 0$ & $\approx 0$ & $\approx 0$ & 0.1 & 0.30 & 1.3 & 1.1 & 0.6 & 9.6 & 30.3 \\
\hline \multicolumn{11}{|c|}{$\begin{array}{c}\text { Operational uncertainties }\left(u_{\mathrm{op}}\right) \\
\text { 1. Thermal effect }\end{array}$} \\
\hline GLO & $\approx 0$ & 1.0 & 0.3 & 0.3 & 0.3 & $\approx 0$ & 1.0 & 0.3 & 0.3 & 0.3 \\
\hline DIF & 0.3 & $\approx 0$ & 0.3 & 0.3 & 0.3 & 0.3 & $\approx 0$ & 0.3 & 0.3 & $\approx 0$ \\
\hline \multicolumn{11}{|c|}{ 2. Directional error } \\
\hline GLO & 33.3 & 33.3 & 33.3 & 8.3 & 33.3 & 33.3 & 33.3 & 33.3 & 8.3 & 33.3 \\
\hline \multicolumn{11}{|c|}{ 3. Soiling } \\
\hline DIR & 0.0 & 0.0 & 0.1 & $\approx 0$ & $\approx 0$ & 16.7 & 4.2 & 26.0 & 2.3 & 1.0 \\
\hline \multicolumn{11}{|c|}{ 4. Leveling } \\
\hline GLO & 0.0 & 0.0 & 0.1 & 0.1 & 0.1 & 15.0 & 16.7 & 21.6 & 27.1 & 21.1 \\
\hline
\end{tabular}

such as the longwave net flux as the offsets are in the order of a few $\mathrm{W} \mathrm{m}^{-2}$. Therefore, the calculated median nighttime values of the GLO and DIF measurements are taken to estimate this uncertainty term (expanded uncertainty values). Results of all ARAD sites are detailed in Tables 4-6.

The last term in Eq. (2) $u_{o p}$ expresses a sum of uncertainties that depend on the operational conditions and the maintenance level. These include soiling effects, leveling-induced errors (only for GLO as the influence on DIF is assumed negligible) and a directional error also referred to as cosine response uncertainty (only for GLO). The latter is not proportional to the voltage signal (and only relevant at times with DIR $>0 \mathrm{~W} \mathrm{~m}^{-2}$ ) and provided by the instrument manufacturer. For CMP21 and CM22 sensors used in ARAD these numbers are $<10 \mathrm{~W} \mathrm{~m}^{-2}$ and $<5 \mathrm{~W} \mathrm{~m}^{-2}$, respectively. Influence of soiling effects (excluding e.g., soiling by birds) is generally anticipated to be larger for pyrheliometers than for pyranometers (due to collimation) (Geuder and Quaschning, 2006; Michalsky et al., 1988; Myers et al., 2001). Following the results of Vuilleumier et al. (2014) the effect of soiling should be well below the $1 \%$ level for regularly maintained instruments (i.e., cleaning performed at least several times a week). Therefore within ARAD, potential soiling errors are neglected for pyranometer measurements (GLO, $\mathrm{DIF}$ ), and a tentative value of $0.2 \%$ (SON, isolated high altitude site), $0.3 \%$ (KSO, alpine site at mid elevation), $0.4 \%$
(GRZ, urban site with daily maintenance), $0.8 \%$ (WHW, urban site with weekly maintenance) and $1.0 \%$ (IBK, urban site with less maintenance than WHW) soiling error is assumed for the pyrheliometer measurements (DIR). Finally, leveling-induced errors are only relevant for GLO measurements as these are induced by a tilt of the instrument during operation, leading to an imprecise projection on an exact horizontal surface. Therefore, this error is a function of the azimuth and inclination of the tilted sensor, solar position and ratio of direct to global radiation. As ARAD radiometers are mounted on moving sun tracking systems additional (diurnal) variations of this tilt would need to be considered which are neglected here. Following coarse estimates from case studies performed at several ARAD sites, this suntrackerinduced leveling error may be in the order of a few tenths of degrees. Once an error on the leveling of the pyranometer is identified, it can be trigonometrically corrected in postprocessing. Ideally this is achieved by e.g., a digital level that logs the exact tilt and is mounted on the moving platform. In operational practice at ARAD sites a bubble level mounted on the pyranometers and pyrgeometers is controlled during maintenance; if the bubble is more than half outside a reference circle, the respective sensor has to be releveled by the on-site staff.

The leveling-induced uncertainty is estimated as follows: from operational experience (during the daily maintenance 
Table 7. Same as Tables 4-6, but combined uncertainties affecting shortwave measurements at all ARAD sites. Relative combined expanded values are marked in bold to allow the comparison with BSRN target accuracies (see Sect. 2.1).

\begin{tabular}{|c|c|c|c|c|c|c|c|c|c|c|}
\hline & \multicolumn{10}{|c|}{ Expanded $\left(\mathrm{W} \mathrm{m}^{-2}\right)$} \\
\hline & WHW & GRZ & $\begin{array}{c}\text { ss } \\
\text { IBK }\end{array}$ & KSO & SON & WHW & GRZ & $\begin{array}{c}\text { ls } \\
\text { IBK }\end{array}$ & KSO & SON \\
\hline DIR & 1.7 & 1.7 & 2.0 & 0.9 & 1.3 & 16.8 & 14.6 & 16.9 & 16.0 & 16.4 \\
\hline GLO & 11.4 & 11.6 & 11.5 & 5.9 & 11.5 & 24.3 & 24.9 & 25.0 & 28.7 & 22.5 \\
\hline \multirow[t]{3}{*}{ DIF } & 1.9 & 1.8 & 2.1 & 1.8 & 1.9 & 9.9 & 9.8 & 10.2 & 14.2 & 13.3 \\
\hline & \multicolumn{10}{|c|}{ Expanded (\%) } \\
\hline & WHW & GRZ & $\begin{array}{l}\text { ss } \\
\text { IBK }\end{array}$ & KSO & SON & WHW & GRZ & $\begin{array}{l}\text { ls } \\
\text { IBK }\end{array}$ & KSO & SON \\
\hline DIR & $\mathbf{3 . 3 3}$ & 3.48 & 4.04 & 1.72 & 2.62 & 1.68 & 1.46 & 1.69 & 1.6 & 1.64 \\
\hline GLO & 22.88 & 23.25 & 23.04 & 11.84 & 22.95 & 2.43 & 2.49 & 2.5 & 2.87 & 2.25 \\
\hline \multirow[t]{3}{*}{ DIF } & 3.86 & 3.55 & 4.28 & 3.51 & 3.74 & 1.98 & 1.97 & 2.03 & 2.83 & 2.66 \\
\hline & \multicolumn{10}{|c|}{ Standard $\left(\mathrm{W} \mathrm{m}^{-2}\right)$} \\
\hline & & & ss & & & & & ls & & \\
\hline DIR & $\begin{array}{l}\text { WHW } \\
0.9\end{array}$ & $\begin{array}{l}\text { GRZ } \\
0.9\end{array}$ & $\begin{array}{l}\mathrm{IBK} \\
1.0\end{array}$ & $\begin{array}{c}\mathrm{KSO} \\
0.4\end{array}$ & $\begin{array}{l}\text { SUN } \\
0.7\end{array}$ & $\begin{array}{l}\text { WHW } \\
8.6\end{array}$ & $\begin{array}{l}\text { GRZ } \\
7.5\end{array}$ & $\begin{array}{c}1 \mathrm{lBK} \\
8.6\end{array}$ & $\begin{array}{l}\mathrm{KSO} \\
8.2\end{array}$ & $\begin{array}{c}\text { SUN } \\
8.4\end{array}$ \\
\hline GLO & 5.8 & 5.9 & 5.9 & 3.0 & 5.9 & 12.4 & 12.7 & 12.7 & 14.6 & 11.5 \\
\hline \multirow[t]{4}{*}{ DIF } & 1.0 & 0.9 & 1.1 & 0.9 & 1.0 & 5.1 & 5.0 & 5.2 & 7.2 & 6.8 \\
\hline & \multicolumn{10}{|c|}{$\sum c_{i}^{2} u_{i}^{2}\left(\mathrm{~W}^{2} \mathrm{~m}^{-4}\right)$} \\
\hline & & & ss & & & & & ls & & \\
\hline & WHW & GRZ & IBK & KSO & SON & WHW & GRZ & IBK & KSO & SON \\
\hline DIR & 0.7 & 0.8 & 1.1 & 0.2 & 0.5 & 73.4 & 55.7 & 74.3 & 66.4 & 70.4 \\
\hline GLO & 34.1 & 35.2 & 34.6 & 9.1 & 34.3 & 153.7 & 161.5 & 162.2 & 214.0 & 131.8 \\
\hline DIF & 1.0 & 0.8 & 1.2 & 0.8 & 0.9 & 25.6 & 25.2 & 26.9 & 53.2 & 45.9 \\
\hline
\end{tabular}

phase) in the ARAD network we estimate an average maximum slope of the sensor tilt of $1^{\circ}$. Then $10 \mathrm{~min}$ averages of quality-controlled, measured DIR projected on the horizontal $\left(\right.$ DIR $\left._{\text {hor }}\right)$ and DIF values over a full annual cycle are used as input in a radiative transfer model (using a simple isotropic assumption for diffuse radiation) to calculate the equivalent GLO value for a $1^{\circ}$ tilted surface $\left(\mathrm{GLO}_{\text {tilt }}\right)$ and all azimuth directions in steps of $1^{\circ}$. A statistical analysis of the daily sums of the difference $\left(\mathrm{DIR}_{\text {hor }}+\mathrm{DIF}\right)-\mathrm{GLO}_{\text {tilt }}$ for all azimuth directions of the sensor tilt is performed to deduce an annual average of the daily maximum (worst azimuth) relative leveling-induced error in GLO on a site basis.

Results of the relative contributions of the individual standard uncertainties $u_{i}$ and the combined expanded uncertainties $U_{i}$ for all five ARAD stations are given in Tables 4-6.

Relative and absolute numbers of the combined expanded uncertainty for all ARAD sites (Table 7) can be directly compared with the BSRN target accuracies (see Sect. 2.1). Values for the combined expanded uncertainties of the ARAD sites range between 1.46 and $2.87 \%$ (or 15 to $29 \mathrm{~W} \mathrm{~m}^{-2}$ for GLO and DIR and 7.5 to $14.5 \mathrm{~W} \mathrm{~m}^{-2}$ for DIF) for large signals and from 1.7 to $23 \%$ (or 0.9 to $11.6 \mathrm{~W} \mathrm{~m}^{-2}$ ) for small signals; thereby it is important to note that largest relative uncertainties $(>4.28 \%)$ at all ARAD sites are found for a small signal of GLO (11.84-23.25\%, or 6-12 $\left.\mathrm{W} \mathrm{m}^{-2}\right)$. As suggested by the relative uncertainty contributions in Tables $4-6$, this is mainly due to the directional error of the pyranometers.
If this error and two minor ones (temperature dependency of DAQ and instruments) are corrected using the calibration certificate of the individual sensors, the combined expanded uncertainties reduce to a range of $1.4-2.8 \%$ (or $14-28 \mathrm{~W} \mathrm{~m}^{-2}$ for GLO and DIR and $7-14 \mathrm{~W} \mathrm{~m}^{-2}$ for DIF) for large signals and to $1.7-5.2 \%$ (or $0.9-2.6 \mathrm{~W} \mathrm{~m}^{-2}$ ) for small signals. Thus, for large signals of GLO and DIF, BSRN target accuracies are met or nearly met (missed by less than 0.2 percentage points, pps) for $70 \%$ of the ARAD measurements after this correction. For small signals of DIR, absolute BSRN targets $\left(1.5 \mathrm{~W} \mathrm{~m}^{-2}\right)$ are achieved at two sites and nearly met (missed by less than $0.2 \mathrm{~W} \mathrm{~m}^{-2}$ ) at the other sites. For small signals of GLO and DIF, BSRN targets are achieved at all stations. Enhanced uncertainty analysis suggest that for GLO and DIF further uncertainty reductions are possible with a better DAQ (such as used at ARAD site KSO), an annual instead of biennial recalibration of the instruments and the corrections of thermal offsets. For DIR, the sensitivity of the instrument is the main uncertainty and BSRN targets of $0.5 \%$ or $1.5 \mathrm{~W} \mathrm{~m}^{-2}$ seem not to be achievable with the current commercially available instrumentation as also indicated by Vuilleumier et al. (2014). 


\section{Data policy, allocation and examples of use}

\subsection{Data policy}

ARAD data are available upon request from ZAMG for "bona fide research purposes", without commercial application or intentions in mind. A formal agreement has to be signed by the user to confirm the intentions of use and additional obligations related to the publication and use of the data. Quality-controlled data from the ARAD and BSRN SON station are transferred on a monthly basis to the BSRN archive and are available there. An RSS feed for the latest data from SON is available here: http://www.pangaea. de/tools/latest-datasets.rss?q=Project:BSRN+SON. General contact information about the ARAD project as well as an information folder (in German and English; in PDF format) for the general public is available on the ZAMG website (https://www.zamg.ac.at/cms/de/forschung/ klima/datensaetze/arad). Figure 5 shows an ARAD data snippet, displaying seasonal mean daily courses for GLO, DIR, DIF and DLW at all five ARAD sites for a full annual cycle.

\subsection{Examples of use of ARAD data}

\subsubsection{Improving sunshine duration observations}

Within a research project at ZAMG, a method provided by Forgan and Dyson (2004) to use 1 min radiation data statistics based on $1 \mathrm{~Hz}$ sampling as recorded in ARAD (average, minimum, maximum, standard deviation) to improve the calculation of sunshine duration from pyrheliometer measurements was tested and compared to $1 \mathrm{~Hz}$ records of a NIP pyrheliometer and measurements from a conventional sunshine duration sensor (Haenni-Solar, used at the TAWES stations of ZAMG) at the WHW station for a period of 4 months. The excellent agreement between the calculations based on the Forgan and Dyson (2004) method and the NIP data (average daily differences of $3.7 \mathrm{~min}(0.8 \%)$ of sunshine duration) suggests that ARAD stations can serve as regional references for sunshine duration measurements in Austria, aiding the continuous improvement and verification of the routine TAWES measurements.

\subsubsection{Validation of ECMWF forecasts}

Forecasting cloudiness and surface radiation remains a major challenge for numerical weather prediction models, and high-accuracy ground-based data are needed for model development/improvement and validation. BSRN and ARAD measurements are used at the European Centre for MediumRange Weather Forecasts (ECMWF) to evaluate forecasts of downward fluxes of shortwave and longwave radiation. Figure 6 shows verification results for Vienna for the period 1 January-31 December 2012. Two features during this intercomparison interval are worth noting. (1) There is a strong drop in correlation between observations and model output,

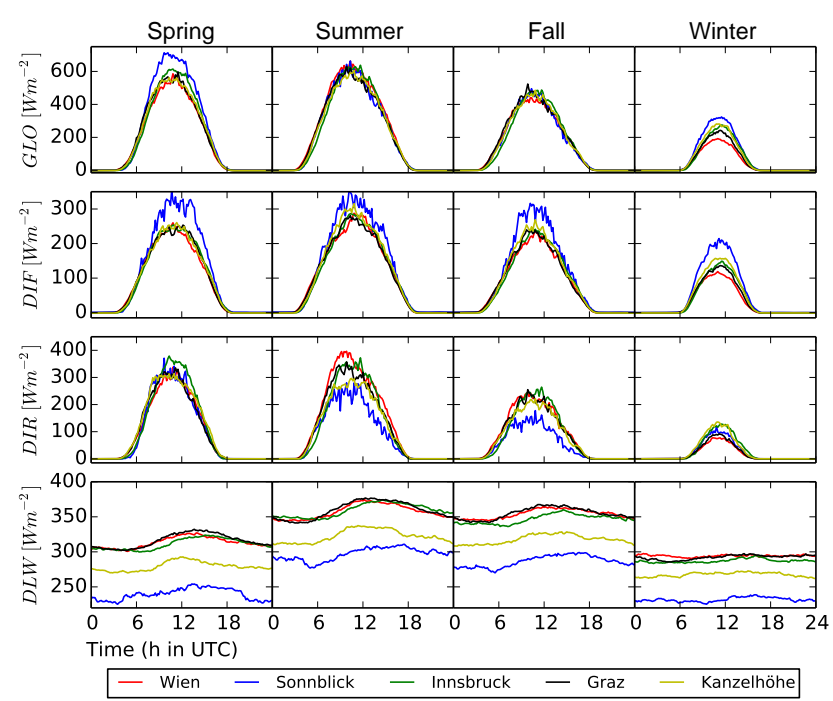

Figure 5. Seasonal mean daily courses based on 10 min averages of the recorded and quality-controlled $1 \mathrm{~min}$ average values for all measured irradiance quantities at all ARAD stations for the full annual cycle 1 December 2013 to 30 November 2014.

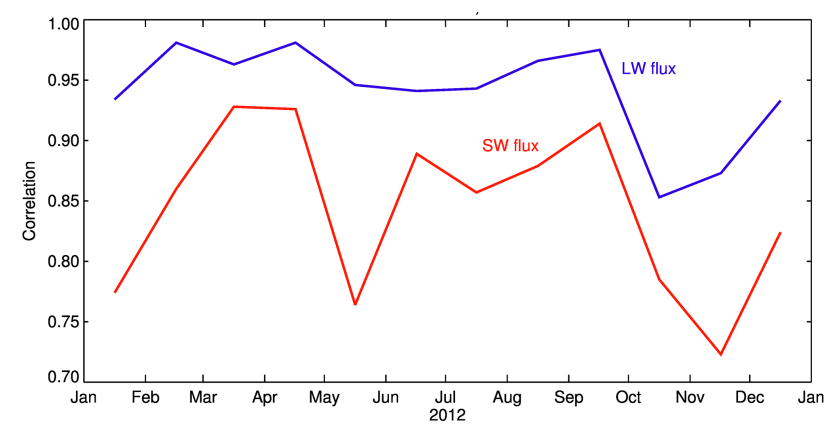

Figure 6. Correlation between short-range (0-24h) forecasts and observations of daily averaged values of downward shortwave and longwave flux at the ARAD WHW station. Monthly means for the verification period 1 Janary-31 December 2012 are shown.

in both the shortwave and longwave range, during autumn. This is a recurring issue in the ECMWF model due to difficulties in representing low stratus clouds. As documented in Haiden and Trentmann (2015) this model deficiency affects forecasts over large parts of Central Europe. (2) A transient drop of the shortwave flux occurred in May, triggered by the prevalent weather situation, i.e., a humid and relatively unstable air mass with weak pressure gradients was present over Austria at that time. Because of the absence of significant synoptic-scale forcing, cloud formation was mainly governed by mesoscale processes, which are less well represented in the model due to limited resolution (16 km in 2012). This created relatively large daytime forecast errors, over the course of several days, affecting the monthly average of the shortwave skill. In addition to the monitoring/evaluation of the operational forecast, surface radiation measurements are 
also used at ECMWF in the evaluation of new model versions, and for assessing the quality of satellite-derived radiation products.

\subsubsection{Analysis and forecasts of radiation and snow}

The cloud parameterization scheme for diffuse solar radiation of the solar radiation model STRAHLGRID, developed at ZAMG (Olefs and Schoener, 2012), to provide gridded data sets of near-surface solar direct and diffuse radiation in near-real time (based on the INCA nowcasting system), was developed using ARAD DIF measurements. The so-called HIM ratio factor is thereby defined by the ratio of measured all-sky to modeled clear-sky diffuse radiation correlated with MSG-2 satellite cloud types. More details on the model and model performance can be found in Sect. 2.3 of the paper by Olefs et al. (2013) that also describes the coupling to the operational energy-balance snow-cover model SNOWGRID, showing the added value of ARAD data for applications in alpine hydrology and cryosphere.

Recently, a method to improve area-wide $72 \mathrm{~h}$ DIR forecasts, driven by atmospheric data of the ALARO numerical weather prediction model used at ZAMG through a coupling of the high-resolution STRAHLGRID model, was successfully tested at ZAMG. For stations with significant horizon shading, a reduction of the root-mean-square error (RMSE) of $3-40 \%$ could be achieved due to the better resolved topography. For stations in the lowlands, an improved cloudiness scheme in STRAHLGRID based on ARAD data led on average to a RMSE reduction of $25 \%$.

\section{Discussion}

Following the uncertainty analysis documented in this paper, there may be three future activities: (1) correction of some of the identified uncertainty sources in the data will be possible during post-processing (e.g., cosine response, thermal offset, leveling, temperature dependence, influence of soiling) which will partly need additional measurements (no correction for historical data possible, e.g., record leveling, with a digital level for every sun-tracker) or experiments (historical data correction possible by capping for daytime thermal offsets, soiling, by analyzing data after as opposed to before maintenance) or simply using the calibration certificates as was demonstrated (historical data correction possible, e.g., directional response error), thereby reducing the combined uncertainties given in Table 7 closer towards BSRN targets. (2) It may become necessary to provide these uncertainty calculations operationally as meta-information, in addition to the allocated data using measured irradiances in the full time resolution $(1 \mathrm{~min})$ and technical specifications of the individual sensors. As some of the uncertainty components depend also on the actual short-term fluctuations of the meteorological conditions (e.g., the directional or leveling error is only relevant when DIR >0) this would allow the user to better judge the actual uncertainty of the delivered data snippet, especially in relation to the uncertainty inherent to e.g., a model run or measurements by a different instrument. (3) Comparison of redundantly measured parameters (e.g., GLO vs. DIF when DIR $=0$, or GLO vs. the component sum DIR $_{\text {hor }}+$ DIF), as done in Vuilleumier et al. (2014), could be carried out to check the plausibility of the derived uncertainty values.

For some of the uncertainty components such as thermal offsets for pyranometer measurements, attempts were undertaken to improve the error correction with the currently available data. In correlation experiments of the nighttime offsets with the longwave net flux, a rather low coefficient of determination of 0.31 was found and even multiple correlations, including additionally e.g., the air temperature, wind speed, case temperatures or the clear-sky index (Marty and Philipona, 2000), the latter related to cloud cover, could only increase $r^{2}$ towards 0.56 . We attribute this rather poor performance to the stepwise signals of the nighttime offsets induced by our DAQ resolution as correlations found in most other studies are significantly higher. Our current approach using the median of the observed nighttime values of the GLO and DIF pyranometer signals at the individual stations has two drawbacks: (1) it is a time-constant, bias-like uncertainty estimation and not an uncertainty expressed as a function of changing meteorological conditions triggering the thermal offsets; (2) it only captures nighttime thermal offsets; and as daytime offsets have the same sign but are roughly 2-3 times larger than nighttime offsets (Sanchez et al., 2015) and references therein), the average uncertainty is certainly underestimated. Over the next years changes in the DAQ are planned within the ARAD network to increase the resolution and accuracy of the voltage measurement and thus aid further analysis of potential nighttime offsets.

A comparable uncertainty estimate for DLW was beyond the scope of this study and is left for future work. However, comparing the average expanded sensitivity uncertainty of our CGR4 pyrgeometers of $4.1 \%$ (see Table 1) with the BSRN target of $2 \%$ suggests that targets are not met because operational and other uncertainties add to this value of sensitivity uncertainty. We note that to date we did not investigate a possible sensitivity of the calibration coefficients of our CGR4 pyrgeometers with respect to integrated water vapor (IWV) related to dome spectral transmissivity as suggested by Gröbner et al. (2014), especially for climates with low IWV values. However, this issue might be of minor importance for ARAD as all ARAD CGR4 pyrgeometers were built after the year 2003. Recent results suggest that those instruments suffer much less from the IWV dependency issue (Gröbner and Wacker, 2013).

\section{$7 \quad$ Summary and conclusions}

We presented the Austrian RADiation monitoring network (ARAD), comprising currently five stations, which largely 
follows the quality standards and guidelines of BSRN. One ARAD site, Sonnblick (SON), has been part of the BSRN network since January 2013.

Our main conclusion is that ARAD could serve as a useful example for establishing state-of-the-art radiation monitoring at the national level with a multiple-purpose approach. In particular, we hope that our experiences will give a stimulus for radiation monitoring in other countries/regions worldwide, which is of utmost importance for climate change research. Instrumentation, guidelines and tools (such as the data quality control) developed within ARAD are best practices which could be easily adopted for other regions.

The consistently defined measurement methods and automated and manual data quality control mechanisms present some innovative aspects to increase data availability and quality. Special care is taken at the ARAD/BSRN SON station, where rough weather conditions necessitate a strict control, regular maintenance and adapted measurement methods. Average combined quality flags (automated and manual controls) of the last 3 years of operation indicate a high ratio of $74-85 \%$ and $91-99 \%$ of data judged as good by those strict checks for stations SON and the other stations, respectively.

A detailed combined uncertainty analysis of the shortwave radiation fluxes at all five ARAD stations indicates that the combined expanded uncertainties range between 1.46 and $2.87 \%$ (or 15 to $29 \mathrm{~W} \mathrm{~m}^{-2}$ for GLO and DIR and 7.5 to $14.5 \mathrm{~W} \mathrm{~m}^{-2}$ for DIF) for large signals and from 1.7 to $23 \%$ (or 0.9 to $11.5 \mathrm{~W} \mathrm{~m}^{-2}$ ) for small signals. The large expanded uncertainties $(>4.28 \%)$ at all ARAD sites are found for a small signal of GLO (11.84-23.25\%, or 6-12 $\left.\mathrm{W} \mathrm{m}^{-2}\right)$ and due to a directional error of the pyranometers that is currently not corrected for but can be corrected retrospectively using the calibration certificate of each instrument. Doing this would mean that for large signals of GLO and DIF, BSRN target accuracies are met or nearly met (missed by less than 0.2 percentage points, pps) for $70 \%$ of the ARAD measurements, and for small signals of direct radiation, absolute BSRN targets $\left(1.5 \mathrm{~W} \mathrm{~m}^{-2}\right)$ are achieved at two sites and nearly met (also missed by less than $0.2 \mathrm{~W} \mathrm{~m}^{-2}$ ) at the other sites. For small signals of GLO and DIF, targets are achieved at all stations. For small signals of GLO and DIF, the accuracy could be further increased by using an even better data acquisition system, a more frequent recalibration of the instruments and a correction of thermal offset errors. Our results agree with previous work (Vuilleumier et al., 2014), indicating that the BSRN target accuracies of DIR can only be achieved with improved instruments. Corrections of the historical data and additional measurements in the future will help to further reduce those uncertainties. Furthermore, the operational calculation of these uncertainties and the inclusion as meta-information together with the measured and quality-controlled data is planned as a service for the community.

Besides meeting the requirements of a national climate monitoring network, ARAD data can serve the international climate research and impact communities as well as practical applications related to solar energy. Thus, ARAD provides comprehensive, high-quality and consistent irradiance reference data for comparison with satellite measurements, model simulations (regional climate models, numerical weather prediction models, energy balance models) and other measurement systems (e.g., sunshine duration or radiation). 


\section{Appendix A: Additional quality criteria}

Here we summarize the quality criteria used in the automated QC (see Sect. 3.2.2) of the ARAD data that are not described in the study of Long and Shi (2008).

1. Based on experience, for every $1 \mathrm{~min}$ time step $t_{i}$ we compare the measured sunshine duration (SSD) of the collocated TAWES station using a Haenni Solar 111B sunshine detector (sum of seconds with sunshine within $1 \mathrm{~min}$ ) with the $1 \mathrm{~min}$ average value of the ARAD DIR measurement. An error occurs if one of the two following conditions is met:

$$
\begin{aligned}
& \operatorname{DIR}\left(t_{i}\right)>100 \mathrm{~W} \mathrm{~m}^{-2} \& \operatorname{SSD}\left(t_{i}\right)=0 \\
& \operatorname{DIR}\left(t_{i}\right)=0 \mathrm{~W} \mathrm{~m}^{-2} \& \operatorname{SSD}\left(t_{i}\right)=60 .
\end{aligned}
$$

2. For every $1 \mathrm{~min}$ time step $t_{i}$ we compare the current $\mathrm{Hv}$ of the heating and ventilation systems of all pyranometers and pyrgeometers to a defined threshold $\mathrm{Hv}_{\text {lim }}$ that depends on the measured parameter (and ARAD station) and ranges between 0.1 and $0.3 \mathrm{~A}$. An error occurs if the following condition is met:

$$
\operatorname{Hv}\left(t_{i}\right)<\mathrm{Hv}_{\text {lim }}
$$

3. For every $1 \mathrm{~min}$ time step $t_{i}$ we compare 1 min average values of $\mathrm{GLO}_{\mathrm{ARAD}}$ and $\mathrm{DIF}_{\mathrm{ARAD}}$ (the latter only at ARAD stations WHW and GRZ) measured at the collocated TAWES site (GLOTAWES, DIF TAWES $_{\text {TAW. An error }}$ occurs if one of the two following conditions is met:

$$
\begin{aligned}
& \left|\operatorname{GLO}_{\text {ARAD }}\left(t_{i}\right)-\operatorname{GLO}_{\text {TAWES }}\left(t_{i}\right)\right|>50 \mathrm{~W} \mathrm{~m}^{-2} \\
& \mid \operatorname{DIF}_{\text {ARAD }}\left(t_{i}\right)-\operatorname{DIF} \text { TAWES }\left(t_{i}\right) \mid>70 \mathrm{Wm}^{-2}
\end{aligned}
$$

4. To detect outliers we compare the difference of the actual $1 \mathrm{~min}$ average value of all irradiances and the respective daily averages $\left(\mathrm{GLO}_{\text {mean }}, \ldots\right)$ to a multiple (mult) of the standard deviations $\left(\mathrm{GLO}_{\mathrm{SD}}, \ldots\right)$ of these quantities for every 1 min time step $t_{i}$. The dimensionless factor mult is thereby calculated based on data analysis, for each station and parameter and ranges between 1.5 and 4. An error occurs if the following condition is met (example shown only for GLO):

$\left(\mathrm{GLO}\left(t_{i}\right)-\mathrm{GLO}_{\text {mean }}\right)>$ mult $\cdot \mathrm{GLO}_{\mathrm{SD}}$ 
Acknowledgements. The ARAD project is financed in part by the Austrian Federal Ministry of Science, Research and Economy. The authors thank Martin Mair for his essential and valuable technical support since the start of the ARAD Project.

Edited by: C. Ammann

\section{References}

Auer, I., Böhm, R., Jurkovic, A., Lipa, W., Orlik, A., Potzmann, R., Schöner, W., Ungersböck, M., Matulla, C., Briffa, K., Jones, P., Efthymiadis, D., Brunetti, M., Nanni, T., Maugeri, M., Mercalli, L., Mestre, O., Moisselin, J.-M., Begert, M., MüllerWestermeier, G., Kveton, V., Bochnicek, O., Stastny, P., Lapin, M., Szalai, S., Szentimrey, T., Cegnar, T., Dolinar, M., GajicCapka, M., Zaninovic, K., Majstorovic, Z., and Nieplova, E.: HISTALP - historical instrumental climatological surface time series of the Greater Alpine Region, Int. J. Climatol., 27, 17-46, doi:10.1002/joc.1377, 2007.

Augustine, J. A., DeLuisi, J. J., and Long, C. N.: SURFRAD - A National Surface Radiation Budget Network for Atmospheric Research, B. Am. Meteorol. Soc., 81, 2341-2357, doi:10.1175/1520-0477(2000)081<2341:SANSRB>2.3.CO;2, 2000.

Blumthaler, M., Gröbner, J., Huber, M., and Ambach, W.: Measuring spectral and spatial variations of UVA and UVB sky radiance, Geophys. Res. Lett., 23, 547-550, doi:10.1029/96GL00248, 1996.

Blumthaler, M., Ambach, W., and Blasbichler, A.: Measurements of the spectral aerosol optical depth using a sun photometer, Theor. Appl. Climatol., 57, 95-101, doi:10.1007/BF00867980, 1997.

Bush, B. C., Valero, F. P. J., Simpson, A. S., and Bignone, L.: Characterization of Thermal Effects in Pyranometers: A Data Correction Algorithm for Improved Measurement of Surface Insolation, J. Atmos. Ocean. Tech., 17, 165-175, doi:10.1175/15200426(2000)017<0165:COTEIP>2.0.CO;2, 2000.

Chevallier, F. and Morcrette, J.-J.: Comparison of Model Fluxes with Surface and Top-of-the-Atmosphere Observations, Mon. Weather Rev., 128, 3839-3852, doi:10.1175/15200493(2001)129<3839:COMFWS>2.0.CO;2, 2000.

Dirmhirn, I.: Untersuchungen der Himmelsstrahlung in den Ostalpen mit besonderer Berücksichtigung ihrer Höhenabhängigkeit, Arch. Meteor. Geophy. B, 2, 301-346, 1951.

Dirmhirn, I.: Studie über die Strahlungsvorgänge auf Gletschern, Arch. Meteor. Geophy. B, 8, 31-55, doi:10.1007/BF02260294, 1957.

Dirmhirn, I. and Eaton, F. D.: Some Characteristics of the Albedo of Snow, J. Appl. Meteorol., 14, 375-379, doi:10.1175/15200450(1975)014<0375:SCOTAO>2.0.CO;2, 1975.

Dirmhirn, I. and Trojer, E.: Albedountersuchungen auf dem Hintereisferner, Arch. Meteor. Geophy. B, 6, 400-416, doi:10.1007/BF02242745, 1955.

Dutton, E. G., Michalsky, J. J., Stoffel, T., Forgan, B. W., Hickey, J., Nelson, D. W., Alberta, T. L., and Reda, I.: Measurement of Broadband Diffuse Solar Irradiance Using Current Commercial Instrumentation with a Correction for Thermal Offset Errors, J. Atmos. Ocean. Tech., 18, 297-314, doi:10.1175/15200426(2001)018<0297:MOBDSI>2.0.CO;2, 2001.
Forgan, B. and Dyson, P.: Uncertainty in daily sunshine duration from BSRN minute statistics, 8th BSRN scientific and review workshop, 26-30 July 2004, Exeter, UK, 2004.

Forgan, B. W.: A New Method for Calibrating Reference and Field Pyranometers, J. Atmos. Ocean. Tech., 13, 638-645, doi:10.1175/1520-0426(1996)013<0638:ANMFCR>2.0.CO;2, 1996.

Frei, C.: Daily precipitation statistics in regional climate models: Evaluation and intercomparison for the European Alps, J. Geophys. Res., 108, 2156-2202, doi:10.1029/2002JD002287, 2003.

Fröhlich, C.: History of Solar Radiometry and the World Radiometric Reference, Metrologia, 28, 111-115, doi:10.1088/00261394/28/3/001, 1991.

Geuder, N. and Quaschning, V.: Soiling of irradiation sensors and methods for soiling correction, Sol. Energy, 80, 1402-1409, doi:10.1016/j.solener.2006.06.001, 2006.

Gilgen, H. and Ohmura, A.: The Global Energy Balance Archive (GEBA), B. Am Meteorol. Soc., 80, 831-850, 1999.

Gobiet, A., Kotlarski, S., Beniston, M., Heinrich, G., Rajczak, J., and Stoffel, M.: 21st century climate change in the European Alps - A review, Sci. Total Environ., 493, 1138-1151, doi:10.1016/j.scitotenv.2013.07.050, 2014.

Gröbner, J. and Wacker, S.: Longwave irradiance measurements using IRIS radiometers at the PMOD/WRC-IRS, AIP Conference Proceedings, 1531, 488-491, 2013.

Gröbner, J., Reda, I., Wacker, S., Nyeki, S., Behrens, K., and Gorman, J.: A new absolute reference for atmospheric longwave irradiance measurements with traceability to SI units, J. Geophys. Res.-Atmos., 119, 7083-7090, doi:10.1002/2014JD021630, 2014.

Gröbner, J., Reda, I., Wacker, S., Nyeki, S., Behrens, K., and Gorman, J.: Reply to the comment of R. Philipona on "A new absolute reference for atmospheric longwave irradiance measurements with traceability to SI units": Reply to comment of Dr. Philipona, J. Geophys. Res.-Atmos., 120, 6885-6886, doi:10.1002/2015JD023345, 2015.

Gueymard, C. A.: A review of validation methodologies and statistical performance indicators for modeled solar radiation data: Towards a better bankability of solar projects, Renew. Sustain. Energ. Rev., 39, 1024-1034, doi:10.1016/j.rser.2014.07.117, 2014.

Gupta, S. V.: Measurement Uncertainties, Springer Berlin Heidelberg, Berlin, Heidelberg, Germany, available at: http://link. springer.com/10.1007/978-3-642-20989-5 (last access: 14 January 2016), 2012.

Gupta, S. K., Kratz, D. P., Wilber, A. C., and Nguyen, L. C.: Validation of Parameterized Algorithms Used to Derive TRMM-CERES Surface Radiative Fluxes, J. Atmos. Ocean. Tech., 21, 742-752, doi:10.1175/15200426(2004)021<0742:VOPAUT>2.0.CO;2, 2004.

Haeffelin, M., Kato, S., Smith, A. M., Rutledge, C. K., Charlock, T. P., and Mahan, J. R.: Determination of the Thermal Offset of the Eppley Precision Spectral Pyranometer, Appl. Optics, 40, 472 484, doi:10.1364/AO.40.000472, 2001.

Haiden, T. and Trentmann, J.: Verification of cloudiness and radiation forecasts in the greater Alpine region, Meteorol. Z., 25, $3-$ 15, doi:10.1127/metz/2015/0630, 2015.

Haiden, T., Kann, A., Wittmann, C., Pistotnik, G., Bica, B., and Gruber, C.: The Integrated Nowcasting through Comprehensive Analysis (INCA) System and Its Validation over 
the Eastern Alpine Region, Weather Forecast., 26, 166-183, doi:10.1175/2010WAF2222451.1, 2011.

Haslinger, K., Anders, I., and Hofstätter, M.: Regional climate modelling over complex terrain: an evaluation study of COSMOCLM hindcast model runs for the Greater Alpine Region, Clim. Dynam., 40, 511-529, doi:10.1007/s00382-012-1452-7, 2013.

Intergovernmental Panel on Climate Change: Observations: Atmosphere and Surface, in Climate Change 2013 - The Physical Science Basis, 159-254, Cambridge University Press, Cambridge, UK, available at: http://ebooks.cambridge.org/ref/id/ CBO9781107415324A016 (last access: 29 June 2015), 2014.

International Organization for Standardization: Solar energy - Calibration of field pyrheliometers by comparison to a reference pyrheliometer, ISO 9059, Geneva, Switzerland, 1990.

International Organization for Standardization: Solar energy - Calibration of field pyranometers by comparison to a reference pyranometer, ISO 9847, International Organization for Standardization, Geneva, Switzerland, 1992.

International Organization for Standardization: Solar energy - Calibration of a pyranometer using a pyrheliometer, ISO 9846, Geneva, Switzerland, 1993.

Ji, Q. and Tsay, S.-C.: A novel nonintrusive method to resolve the thermal dome effect of pyranometers: Instrumentation and observational basis, J. Geophys. Res., 115, D00K21, doi:10.1029/2009JD013483, 2010.

Joint Committee for Guides in Measurements (JCGM): Evaluation of measurement data - Guide to expression of uncertainty in measurement, JCGM 100:2008, GUM 1995 with minor corrections, available at: http://www.bipm.org/utils/common/ documents/jcgm/JCGM_100_2008_E.pdf (last access: 18 March 2016), 2008.

König-Langlo, G., Sieger, R., Schmithüsen, H., Bücker, A., Richter, F., and Dutton, E.: The Baseline Surface Radiation Network and its World Radiation Monitoring Centre at the Alfred Wegener Institute, World Meteorological Organization, Geneva, Switzerland, available at: http://www.wmo.int/pages/prog/gcos/ Publications/gcos-174.pdf, 2013.

Kotlarski, S., Lüthi, D., and Schär, C.: The elevation dependency of 21st century European climate change: an RCM ensemble perspective: elevation dependency of 21 st century european climate change, Int. J. Climatol., 35, 3902-3920, doi:10.1002/joc.4254, 2015.

Long, C. N. and Shi, Y.: An Automated Quality Assessment and Control Algorithm for Surface Radiation Measurements, Open Atmospheric Sci. J., 2, 23-37, doi:10.2174/1874282300802010023, 2008.

Marty, C. and Philipona, R.: The clear-sky index to separate clearsky from cloudy-sky situations in climate research, Geophys. Res. Lett., 27, 2649-2652, doi:10.1029/2000GL011743, 2000.

Marty, C., Philipona, R., Fröhlich, C., and Ohmura, A.: Altitude dependence of surface radiation fluxes and cloud forcing in the alps: results from the alpine surface radiation budget network, Theor. Appl. Climatol., 72, 137-155, doi:10.1007/s007040200019, 2002.

McArthur, L. J. B.: World Climate Research Programme - Baseline Surface Radiation Network (BSRN) - Operations Manual Version 2.1, Experimental Studies Division, Atmospheric Environment Service, Downsview, Ontario, Canada, 2005.
Michalsky, J., Dutton, E. G., Nelson, D., Wendell, J., Wilcox, S., Andreas, A., Gotseff, P., Myers, D., Reda, I., Stoffel, T., Behrens, K., Carlund, T., Finsterle, W., and Halliwell, D.: An Extensive Comparison of Commercial Pyrheliometers under a Wide Range of Routine Observing Conditions, J. Atmos. Ocean. Tech., 28, 752-766, doi:10.1175/2010JTECHA1518.1, 2011.

Michalsky, J. J.: Toward the development of a diffuse horizontal shortwave irradiance working standard, J. Geophys. Res., 110, D06107, doi:10.1029/2004JD005265, 2005.

Michalsky, J. J., Perez, R., Stewart, R., LeBaron, B. A., and Harrison, L.: Design and development of a rotating shadowband radiometer solar radiation/daylight network, Sol. Energy, 41, 577581, doi:10.1016/0038-092X(88)90060-6, 1988.

Myers, D. R., Andreas, R., Stoffel, T., Reda, I., Wilcox, S., Gotseff, P., and Kay, B.: Radiometric Calibrations, Measurements, and Standards Development at NREL, National Renewable Energy Laboratory, Lakewood, CO, USA, 2001.

Neuwirth, F.: The estimation of global and sky radiation in Austria, Sol. Energy, 24, 421-426, doi:10.1016/0038-092X(80)90309-6, 1980.

Neuwirth, F.: Die Parameterisierung des prozentualen Verhältnisses zwischen Himmelsstrahlung und Globalstrahlung durch die Bewölkungsmenge, Arch. Meteor. Geophy. B, 33, 243-250, doi:10.1007/BF02275098, 1983.

Ohmura, A., Gilgen, H., Hegner, H., Müller, G., Wild, M., Dutton, E. G., Forgan, B., Fröhlich, C., Philipona, R., Heimo, A., KönigLanglo, G., McArthur, B., Pinker, R., Whitlock, C., and Dehne, $\mathrm{K}$. : Baseline surface radiation network (BSRN/WCRP): new precision radiometry for climate research, B. Am. Meteorol. Soc., 79, 2115-2136, 1998.

Olefs, M. and Schoener, W.: A new solar radiation model for research and applications in Austria, Vienna, Austria, 2012.

Olefs, M., Schöner, W., Suklitsch, M., Wittmann, C., Niedermoser, B., Neururer, A., and Wurzer, A.: SNOWGRID - A New Operational Snow Cover Model in Austria, in Proceedings of the international snow science workshop Grenoble - Chamonix Mont Blanc, 7-11 October 2013, Grenoble, France, 2013.

Philipona, R.: Underestimation of solar global and diffuse radiation measured at Earth's surface, J. Geophys. Res., 107, 4654, doi:10.1029/2002JD002396, 2002.

Philipona, R.: Greenhouse warming and solar brightening in and around the Alps, Int. J. Climatol., 33, 1530-1537, doi:10.1002/joc.3531, 2013.

Philipona, R.: Comment on "A new absolute reference for atmospheric longwave irradiance measurements with traceability to SI units" by Gröbner et al.: Comment to Gröbner et al., 2014, J. Geophys. Res.-Atmos., 120, 6882-6884, doi:10.1002/2014JD022990, 2015.

Ramanathan, V.: The role of earth radiation budget studies in climate and general circulation research, J. Geophys. Res., 92, 4075, doi:10.1029/JD092iD04p04075, 1987.

Reda, I.: Method to Calculate Uncertainties in Measuring Shortwave Solar Irradiance Using Thermopile and Semiconductor Solar Radiometers, Technical Report, NREL, 2011.

Rieder, H. E., Staehelin, J., Weihs, P., Vuilleumier, L., Maeder, J. A., Holawe, F., Blumthaler, M., Lindfors, A., Peter, T., Simic, S., Spichtinger, P., Wagner, J. E., Walker, D., and Ribatet, M.: Relationship between high daily erythemal UV doses, total ozone, surface albedo and cloudiness: An analysis of 30 years 
of data from Switzerland and Austria, Atmos. Res., 98, 9-20, doi:10.1016/j.atmosres.2010.03.006, 2010.

Sanchez, G., Serrano, A., Cancillo, M. L., and Garcia, J. A.: Pyranometer Thermal Offset: Measurement and Analysis, J. Atmos. Ocean. Tech., 32, 234-246, doi:10.1175/JTECH-D-14-00082.1, 2015.

Sauberer, F. and Dirmhirn, I.: Der Strahlungshaushalt horizontaler Gletscherflächen auf dem hohen Sonnblick, Geogr. Ann. A, 34, 261-290, doi:10.2307/520156, 1952.

Vuilleumier, L., Hauser, M., Félix, C., Vignola, F., Blanc, P., Kazantzidis, A., and Calpini, B.: Accuracy of ground surface broadband shortwave radiation monitoring: Shortwave radiation monitoring accuracy, J. Geophys. Res.-Atmos., 119(24), 1383813860, doi:10.1002/2014JD022335, 2014.

Wacker, S., Gröbner, J., Hocke, K., Kämpfer, N., and Vuilleumier, L.: Trend analysis of surface cloud-free downwelling long-wave radiation from four Swiss sites, J. Geophys. Res., 116, D10104, doi:10.1029/2010JD015343, 2011.

Weihs, P., Blumthaler, M., Rieder, H. E., Kreuter, A., Simic, S., Laube, W., Schmalwieser, A. W., Wagner, J. E., and Tanskanen, A.: Measurements of UV irradiance within the area of one satellite pixel, Atmos. Chem. Phys., 8, 5615-5626, doi:10.5194/acp8-5615-2008, 2008.

Weihs, P., Schmalwieser, A., Reinisch, C., Meraner, E., Walisch, S., and Harald, M.: Measurements of Personal UV Exposure on Different Parts of the Body During Various Activities, Photochem. Photobiol., 89, 1004-1007, doi:10.1111/php.12085, 2013.
Weihs, P., Rennhofer, M., Baumgartner, D. J., Gadermaier, J., Wagner, J. E., Gehring, J. E., and Laube, W.: Potential impact of contrails on solar energy gain, Atmos. Meas. Tech., 8, 1089-1096, doi:10.5194/amt-8-1089-2015, 2015.

Wild, M.: Global dimming and brightening: A review, J. Geophys. Res., 114, D00D16, doi:10.1029/2008JD011470, 2009.

Wild, M., Ohmura, A., Gilgen, H., Morcrette, J.-J., and Slingo, A.: Evaluation of Downward Longwave Radiation in General Circulation Models, J. Climate, 14, 3227-3239, doi:10.1175/15200442(2001)014<3227:EODLRI>2.0.CO;2, 2001.

Wild, M., Folini, D., Hakuba, M. Z., Schär, C., Seneviratne, S. I., Kato, S., Rutan, D., Ammann, C., Wood, E. F., and KönigLanglo, G.: The energy balance over land and oceans: an assessment based on direct observations and CMIP5 climate models, Clim. Dynam., 44, 3393-3429, doi:10.1007/s00382-014-2430-z, 2015.

Wuttke, S., Kreuter, A., and Blumthaler, M.: Aerosol climatology in an Alpine valley: aerosol climatology in an alpine valley, J. Geophys. Res.-Atmos., 117, D20202, doi:10.1029/2012JD017854, 2012. 